\title{
Complutum
}

ISSN: 1131-6993

\section{Arroyo de las Almas (La Fregeneda, Salamanca): un nuevo conjunto con arte rupestre en la cuenca del Duero}

\author{
Mário Reis ${ }^{1}$ y Carlos Vázquez Marcos ${ }^{2}$
}

Recibido: 11 de junio de 2019 / Aceptado: 7 de noviembre de 2019

Resumen. El conjunto arqueológico rupestre al aire libre del Arroyo de las Almas, en el municipio salmantino de La Fregeneda, fue descubierto por los autores de este texto a partir de septiembre de 2015. Los trabajos de prospección y documentación desarrollados en los meses subsiguientes a los primeros hallazgos, con el fin de conocer el entorno de manera precisa, nos condujeron a nuevas y relevantes evidencias artísticas, tanto paleolíticas como postpaleolíticas. Como resultado final de estas tareas arqueológicas se han diferenciado 4 núcleos grabados localizados en dicho arroyo y en varios de sus principales afluentes, con 24 rocas de pizarras y esquistos y, aproximadamente, 600 motivos grabados. En este trabajo presentamos una descripción detallada del ambiente geomorfológico y paisajístico de este nuevo conjunto además de una visión general de su repertorio gráfico en cada uno de los cuatro períodos cronoculturales registrados: Paleolítico Superior, Prehistoria Reciente, Edad del Hierro y Época Moderna y Contemporánea.

Palabras clave: Grabados; Paleolítico Superior; Prehistoria Reciente; Edad del Hierro; Época Moderna.

\section{[en] Arroyo de las Almas (La Fregeneda, Salamanca): a new rock art site in the Duero basin}

Abstract. The open-air rock art site of Arroyo de las Almas, in the municipality of La Fregeneda (Salamanca), was discovered by the authors of this text in September 2015. The survey and documentation work carried out in the months following the first discoveries, with the aim of getting to know the site in a precise manner, led us to new and relevant artistic evidences, both Palaeolithic and Postpalaeolithic. As a result of these archaeological works, four different engraved settings have been distinguished in the site, located in the stream and in several of its main tributaries, with 24 schist rocks decorated with approximately 600 engraved motifs. The aim of the present text is to provide a detailed description of the geomorphological and landscape environment of this new ensemble, along with a first and general introduction of its graphic repertoire for each of the four cultural and chronological registered periods: Upper Palaeolithic, Late Prehistory, Iron Age and Modern Age.

Keywords: Engravings; Upper Palaeolithic; Late Prehistory; Iron Age; Modern Age.

Sumario. 1. Introducción. 2. Localización. 3. Antecedentes en el ámbito geográfico más inmediato. 4. Metodología utilizada en la prospección, documentación y estudio de las nuevas evidencias gráficas. 5. Arroyo de las Almas: Descripción y distribución de las rocas decoradas. 5.1. Núcleo I (WGS 84: 4100’55.5”N 654’45.5”W). 5.2. Núcleo II

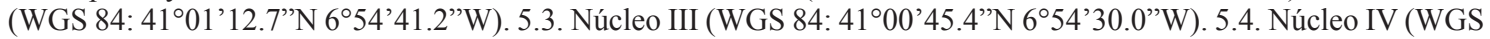

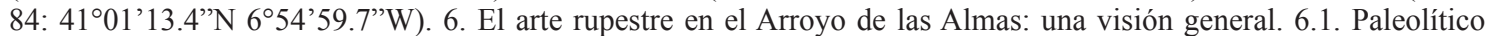
Superior. 6.2. Prehistoria Reciente. 6.3 Edad del Hierro. 6.4. Época Moderna. 7. Consideraciones finales. Fuentes de financiación. Agradecimientos. Bibliografía

Cómo citar: Reis, M. y Vázquez Marcos, C. (2019). Arroyo de las Almas (La Fregeneda, Salamanca): un nuevo conjunto con arte rupestre en la cuenca del Duero. Complutum, 30 (2): 223-245.

1 Centro de Estudos em Arqueologia, Artes e Ciências do Património da Universidade de Coimbra (CEAACP) / Fundação Côa Parque (Portugal). marioreissoares@sapo.pt

2 GIR PREHUSAL. Departamento de Prehistoria, $\mathrm{H}^{\mathrm{a}}$ Antigua y Arqueología. Facultad de Geografía e Historia. (Universidad de Salamanca) y CEM (Centro de Estudios Microbrigenses). carlosvazquezmarcos@gmail.com 


\section{Introducción}

En este artículo queremos dar a conocer los resultados finales de nuestro proyecto de investigación sobre el nuevo conjunto con arte rupestre del Arroyo de las Almas (La Fregeneda, Salamanca), después de su descubrimiento a partir de septiembre de 2015 (Reis y Vázquez Marcos 2015). Para ello, presentamos las principales características de este yacimiento artístico en el que hemos identificado 24 rocas decoradas, con más de 600 motivos grabados con una larga diacronía, que se inicia en el Paleolítico Superior, probablemente entre el Solutrense final y el Magdaleniense antiguo (Vázquez Marcos y Reis 2019), y que se prolonga hasta la Época Moderna y Contemporánea, pasando por la Prehistoria Reciente (ver Apartado 6.2) y la Edad del Hierro (ver Tabla 1).

El establecimiento de esta larga amplitud cronológica, para el conjunto grabado del Arroyo de las Almas, fue planteada tras el análisis estilístico del acervo gráfico inventariado. En primer lugar, observando las principales características de los diferentes motivos, para a continuación separarlos por grupos estilísticos. Con posterioridad comparamos esos mismos grupos detectados, con la realidad gráfica paleolítica y postpaleolítica conocida, tanto a nivel local y regional como peninsular.

De todo ello, resultó que hay un pequeño grupo de motivos que debemos insertar, cronoculturalmente, en el arte Paleolítico, con sólidos paralelos en el contexto euroasiático e ibérico. Estos últimos, como era esperable, se manifestaron, principalmente, en el cercano sitio de Siega Verde (Serranillo, Salamanca); en la cuenca del río Águeda, y en el vecino complejo rupestre del valle del Côa (Portugal).

La prehistoria postglaciar está representada por dos motivos figurativos piqueteados integrables en el universo del arte esquemático peninsular, además de por un amplio conjunto de grabados lineales. Se han de añadir, a este período, el gran grupo regional de grabados denominados como "uñadas del diablo", que tienen una preferente distribución en la cuenca del Duero portugués, y del que las dos rocas detectadas en el Arroyo de las Almas son los mejores ejemplos conocidos en territorio español.

El amplio conjunto de grabados de la Edad del Hierro identificado, destaca, en parte, por su peculiar iconografía y estilo, con evidentes paralelos en la Península Ibérica y, una vez más, con una vigorosa proximidad formal al complejo portugués del Côa, que no impiden destacar la originalidad y especificidad del arte de este momento en Arroyo de las Almas. Esto mismo sucede con los grabados más recientes de Época Moderna y Contemporánea, y que forman el grupo más numeroso de los documentados en el conjunto rayano.

Como podemos intuir por lo antedicho, la colección de grabados es tan grande y diversa que no es fácilmente presentable en un solo trabajo. Por esto mismo, nuestra estrategia de publicación para este importante conjunto rupestre pasa por una presentación, en diferentes artículos, que puedan ser, a su vez, complementarios.

La primera y breve nota sobre el conjunto más antiguo del Paleolítico Superior ya fue presentada (Vázquez Marcos y Reis 2019). En la actualidad, estamos preparando otros textos en detalle, donde abordaremos cada uno de los cuatro períodos cronológicos detectados, incluyendo un nuevo trabajo más amplio y detallado, sobre los grabados del Paleolítico Superior.

De esta forma, el presente texto persigue, sobre todo, tres objetivos. En primer lugar, una presentación de nuestro proyecto de investigación y de la metodología utilizada y resultados obtenidos. En segundo lugar, una síntesis general del conjunto rupestre detectado. Y, finalmente, un compendio detallado sobre el ambiente, la geomorfología y el paisaje en que se insertan las rocas decoradas, para servir de introducción a futuros trabajos.

El hallazgo de estos inéditos grabados aconteció en el transcurso de las prospecciones arqueológicas realizadas gracias al apoyo concedido por el Centro de Estudos de Arqueologia, Arte e Ciências do Património de la Universidad de Coimbra (Portugal) y, especialmente, de su coordinadora científica, Maria da Conceição Lopes. $\mathrm{Su}$ aval científico nos permitió emprender una intensiva prospección arqueológica, proyectada con anterioridad, tras la recepción del correspondiente permiso otorgado por las autoridades competentes, N. ${ }^{\circ}$ EXPTE.: 46/2015-SA SEH/ $\mathrm{CEV}$, en el curso medio-bajo del río Águeda y sus principales afluentes, en territorio español, hasta su desembocadura en el río Duero. Con esta prospección no solo buscábamos escrutar el territorio especificado, con el fin de ampliar el registro gráfico glacial y postglacial, puesto que profundizar en los posibles modelos de ocupación, frecuentación y movilidad humana, $\mathrm{y}$ sus factibles vínculos con el espacio natural de la cuenca del Águeda y del Duero en el que se desarrolló, se nos antojaba igual de necesario y relevante (Reis y Vázquez Marcos 2015: 33). 


\section{Localización}

El conjunto rupestre del Arroyo de las Almas se sitúa en el término municipal de La Fregeneda, en las márgenes de dicho arroyo y en el entorno de varias de sus pequeñas y adyacentes riveras, en la esquina noroccidental de la provincia de Salamanca. Este municipio, y el conjunto descubierto, se encuentran incluidos en la comarca de Vitigudino y en la subcomarca del Abadengo; una zona comprendida entre los ríos Águeda, Yeltes, Huebra y Duero, dentro del Parque Natural Arribes del Duero. Asimismo, es en este amplio territorio de la penillanura circundante al yacimiento, que ya desde el Mesozoico fue modificado por diferentes fenómenos erosivos que hicieron aflorar los materiales del zócalo Paleozoico constituido principalmente por rocas ígneas y metamórficas, donde nace el Arroyo de las Almas: un pequeño afluente del río Águeda cuya desembocadura se encuentra a poco más de $1 \mathrm{~km}$ de la entrada de este último en el Duero.

Ambos ríos, el Águeda y el Duero, son también protagonistas ineludibles en este trabajo, junto al Arroyo de las Almas, siendo los principales artífices de las amplias gargantas y paredes verticales, al continuar las fallas y diaclasas preexistentes, dificultando el ya de por sí complejo trabajo prospectivo desarrollado a lo largo de los años 2015 y 2016 (Fig. 1).

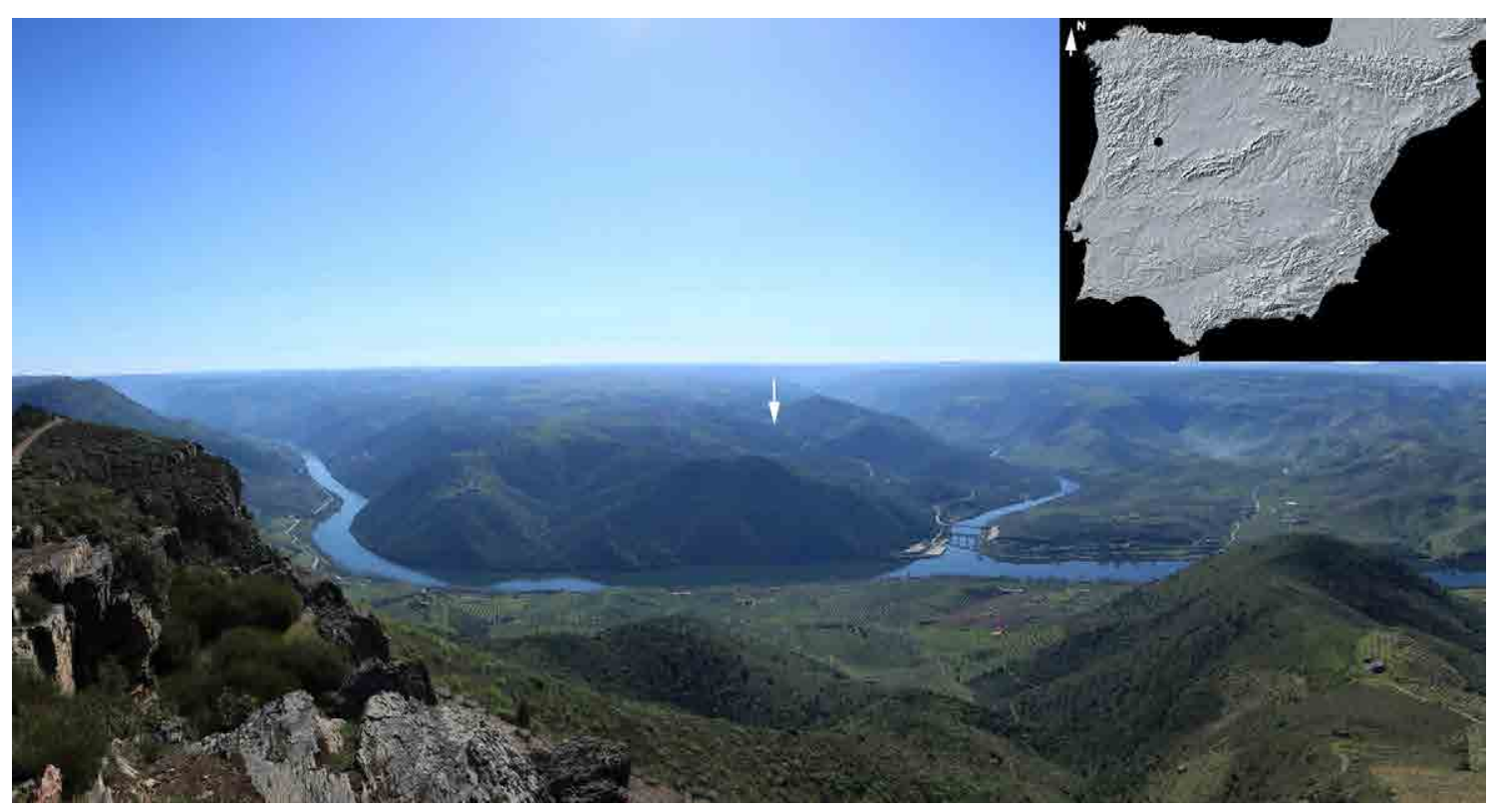

Figura 1. Imagen tomada desde la margen portuguesa del río Duero. En ella se puede observar la desembocadura del Águeda, bajo el puente internacional ferroviario y, señalado por la flecha, el valle del Arroyo de las Almas.

En último término, con respecto a su localización, subrayar que el principal promontorio, del área cercana al sitio arqueológico del Arroyo de las Almas, se sitúa a 473 m. s.n.m., encontrándose cartografiado en la hoja 106 de la Carta Militar española, escala 1: 25.000, siendo sus coordena-

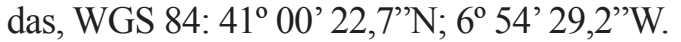

\section{Antecedentes en el ámbito geográfico más inmediato}

Las primeras investigaciones arqueológicas sobre la posible presencia de arte rupestre en el término municipal de La Fregeneda, se desarrollaron en el transcurso de una prospección tras el descubrimiento científico del primer équido del sitio arqueológico de Siega Verde (Serranillo, Salamanca), en octubre de 1988, por Manuel Santonja Gómez. Dicha prospección, llevada a cabo por miembros del Museo de Salamanca, estaba encaminada "a documentar restos artísticos" (Balbín et al. 1991: 3), como así quedó reflejado en los informes inéditos de los trabajos de documentación posteriormente elaborados, no habiéndose hecho constar hallazgo rupestre alguno en el área referida (Alcolea y Balbín 
2008: 57; Balbín et al. 1991: 2-3; Santonja 1998: 50-56).

La ausencia de enclaves inventariados con arte rupestre en este amplio territorio fue corroborada en la correspondiente base de datos de fichas arqueológicas de la Junta de Castilla y León, donde sí están registrados otros sitios con vestigios prehistóricos e históricos, aunque con una tipología diferente a la de nuestro trabajo (Benito del Rey et al. 1993: 315-318; Martín Valls 1998; Santonja 1998). Pese a ello, estos yacimientos fueron reconocidos con la única finalidad de tener una visión más completa del entorno a prospectar.

Tras las nombradas intervenciones arqueológicas acaecidas en los años finales de la década de 1980 y principios de 1990, se inició un período de silencio arqueológico; en lo que atañe a descubrimientos artísticos, en el área final del valle del río Águeda. Quizá, el impacto de Siega Verde y sus relevantes evidencias gráficas Paleolíticas (Alcolea y Balbín 2006; Vázquez Marcos 2018; Vázquez Marcos y Angulo Cuesta 2019), eclipsó el panorama sobre el estudio del arte rupestre prehistórico en este valle, preferentemente en el lado español de la frontera hispano-portuguesa, anulando así otros posibles trabajos de prospección (Vázquez Marcos y Reis 2019).

Esta senda, que había sido abierta con Siega Verde y los sitios rupestres del valle del Côa (Portugal), divulgados en noviembre de 1994 (Baptista y Reis 2008: 149), sí se amplió, por el contrario, en territorio portugués. Aquí, uno de nosotros, descubría en 2011 la roca paleolítica de Redor do Porco (Figueira de Castelo Rodrigo), muy cercana al Arroyo de las Almas (Baptista y Reis 2011). Su desvelo, fue el que nos condujo a los recientes hallazgos que se integran en el denso conjunto artístico al aire libre que tiene como foco principal el valle del Duero, especialmente cuando penetra en Portugal, con el gran conjunto de arte rupestre al aire libre del valle del Côa (Aubry 2009a; Baptista 1999, 2009; Reis 2014; Santos 2017), cuyo epicentro dista pocos kilómetros de la desembocadura del Águeda. Asimismo, debemos de tener en cuenta el similar ámbito paisajístico y geomorfológico entre estos parajes rupestres y el Arroyo de las Almas, incluyendo la forma en que las superficies pizarrosas y esquistosas surgen en posición vertical y se distribuyen por el entorno.

Como veremos más abajo, esta semejanza no solo se extiende a su arte rupestre ya que de igual forma, mostraremos la ineludible conexión entre el conjunto artístico, el espacio natural y los cursos de agua que permiten un fácil franqueo a través de los mismos, vinculando arte y territorio.

\section{Metodología utilizada en la prospección, documentación y estudio de las nuevas evidencias gráficas}

En la prospección arqueológica partimos de un principio metodológico simple: donde hay afloramientos rocosos puede haber arte rupestre, y la única forma de descubrirlo es observar metódicamente las superficies disponibles. Así, y dentro de las áreas para las que se solicitó el permiso de prospección, y que en su totalidad no pudieron ser reconocidas tras los descubrimientos sobre los que versa este estudio, fuimos explorando aquellos lugares donde los afloramientos de pizarras y esquistos eran más visibles (ver áreas prospectadas en la Fig. 2).

En su mayoría, tienen una irregular distribución a lo largo del Arroyo de las Almas, siendo escasos en su margen izquierda, aunque puedan existir algunas zonas dispersas con amplias concentraciones rocosas. En la margen derecha, por el contrario, son más numerosos en los pequeños afluentes de la rivera principal donde ocasionalmente pueden formar grandes grupos rocosos. La desfavorable búsqueda que llevamos a cabo en la desembocadura del Arroyo de las Almas en el río Águeda, fue realizada pese a la casi ausencia de afloramientos. Nuestro objetivo era asegurarnos de que no habría manifestaciones artísticas en este tipo específico de localización, la desembocadura de un río, frecuentemente atractiva para la realización de motivos rupestres, tanto paleolíticos como postpaleolíticos.

Posteriormente se dividió el entorno rastreado, para su mejor comprensión, por núcleos, apoyándonos en un similar modelo de ficha, para la documentación y registro de las evidencias observadas, al empleado en el inventario arqueológico de la comunidad autónoma referida. Tras esto, llevamos a cabo una primera diagnosis, desde la óptica de su conservación, de los motivos y de las superficies con grabados, prestando una especial atención a las alteraciones y pátinas. Esta primera lectura se llevó a cabo con luz natural y artificial, utilizando varias luces de iluminación fría Led, tanto en rocas y paneles como en los motivos catalogados. Asimismo, y tras regis- 
trarse las primeras figuras mediante fotografías diurnas, nocturnas y calcos, llevamos a cabo la preliminar valoración científica de los hallazgos mediante la observación visual en cada sitio, con ayuda de varias lupas de aumento, y posteriormente en el laboratorio.

La elaboración de los calcos, se llevó a cabo apoyándonos en los específicos programas informáticos existentes $\mathrm{y}$, por tanto, a partir de las imágenes obtenidas y digitalizadas con el objetivo de copiarlas y reproducirlas adecuada y fielmente. Queremos incidir no solo en la abundante documentación fotográfica reunida, tanto paisajística; concediéndole la importancia que merece al entorno en el que se conservan las manifestaciones grabadas, como al conjunto rupestre, además de resaltar la trascendencia que tienen dichas capturas para poder amaitinar adecuadamente los detalles formales y técnicos de cada motivo y de los núcleos que forman el conjunto del Arroyo de las Almas. Estas tomas fotográficas se llevaron a cabo en función de la mejor hora del día y de la noche, con una Canon 5D Mark II y diversos objetivos, además de un teleobjetivo, y varios flashes sincronizados en diversas posiciones.

\section{Arroyo de las Almas: Descripción y distribución de las rocas decoradas}

Arroyo de las Almas es un afluente relativamente poco importante que discurre por la margen derecha del río Águeda, próximo a la localidad portuguesa de Barca d'Alva que se encuentra a orillas del Duero, en su margen izquierda. Nacido en un altiplano entre los valles del Duero y del Águeda, a poco más de $3 \mathrm{~km}$ al noroeste del municipio de La Fregeneda, tiene un sinuoso curso que fluye en esa misma dirección hasta que desemboca en el Águeda, a una altura de 130 m. s.n.m. En su acentuado descenso, de casi $300 \mathrm{~m}$., $3600 \mathrm{~m}$. en línea recta desde su nacimiento hasta su desembocadura, que aumenta a $5400 \mathrm{~m}$. si llevamos a cabo esta medición por el lecho del arroyo, debido a su serpenteante recorrido en un valle profundamente excavado (Fig. 2).

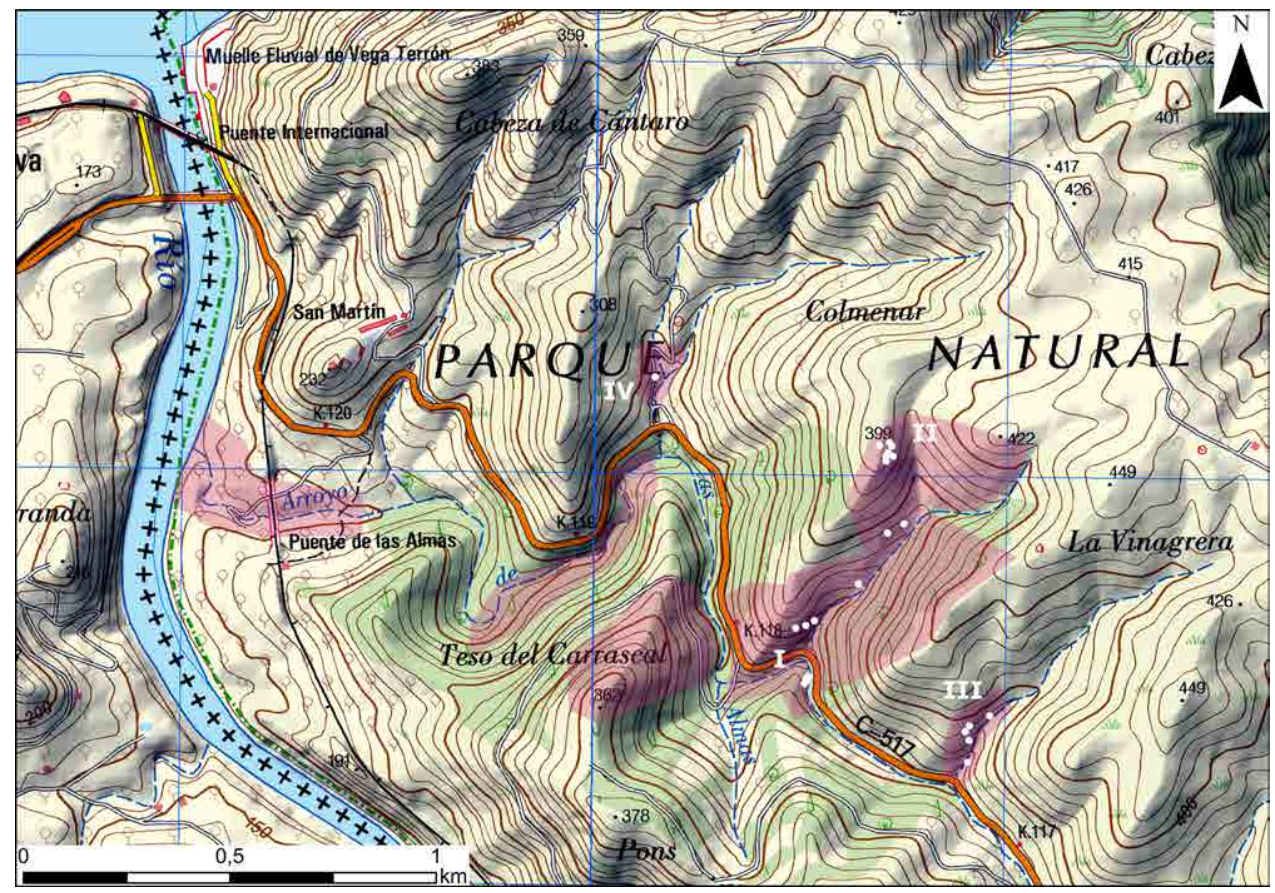

Figura 2. Ubicación cartográfica del Arroyo de las Almas y de los 4 núcleos con grabados.

En semitransparente se delinean las áreas prospectadas, señalando los puntos blancos la situación de las 24 rocas decoradas e inventariadas en los 4 diferentes núcleos (a partir del Mapa Topográfico Nacional de España, escala: 1: 25.000, hoja 106 de la Carta Militar Española).

La margen izquierda del Arroyo de las Almas, con una inclinación que sigue los meandros del río y que hace de separación con el valle del Águeda, es prácticamente continua, estando poco excavada por afluentes laterales. Por el contrario, la margen derecha está interrumpida por una sucesión de pequeños valles, algunos bastante profundos, que nacen en la 
cercana cumbre que hace, a su vez, de transición hacia el valle del Duero.

En general, las márgenes del propio arroyo se presentan con muy pocos afloramientos de pizarras y esquistos, siendo más abundantes a lo largo de los pequeños afluentes de la margen derecha del Arroyo. Quizá por ello, son estos úl- timos valles los que tienen el mayor número de rocas decoradas del conjunto que, con base en su distribución, fueron incluidas en 4 núcleos distintos: los Núcleos I y II en la misma rivera y los Núcleos III y IV ocupando cada uno su propio espacio, en otros dos pequeños afluentes por la margen derecha del Arroyo de las Almas (Fig. 3).
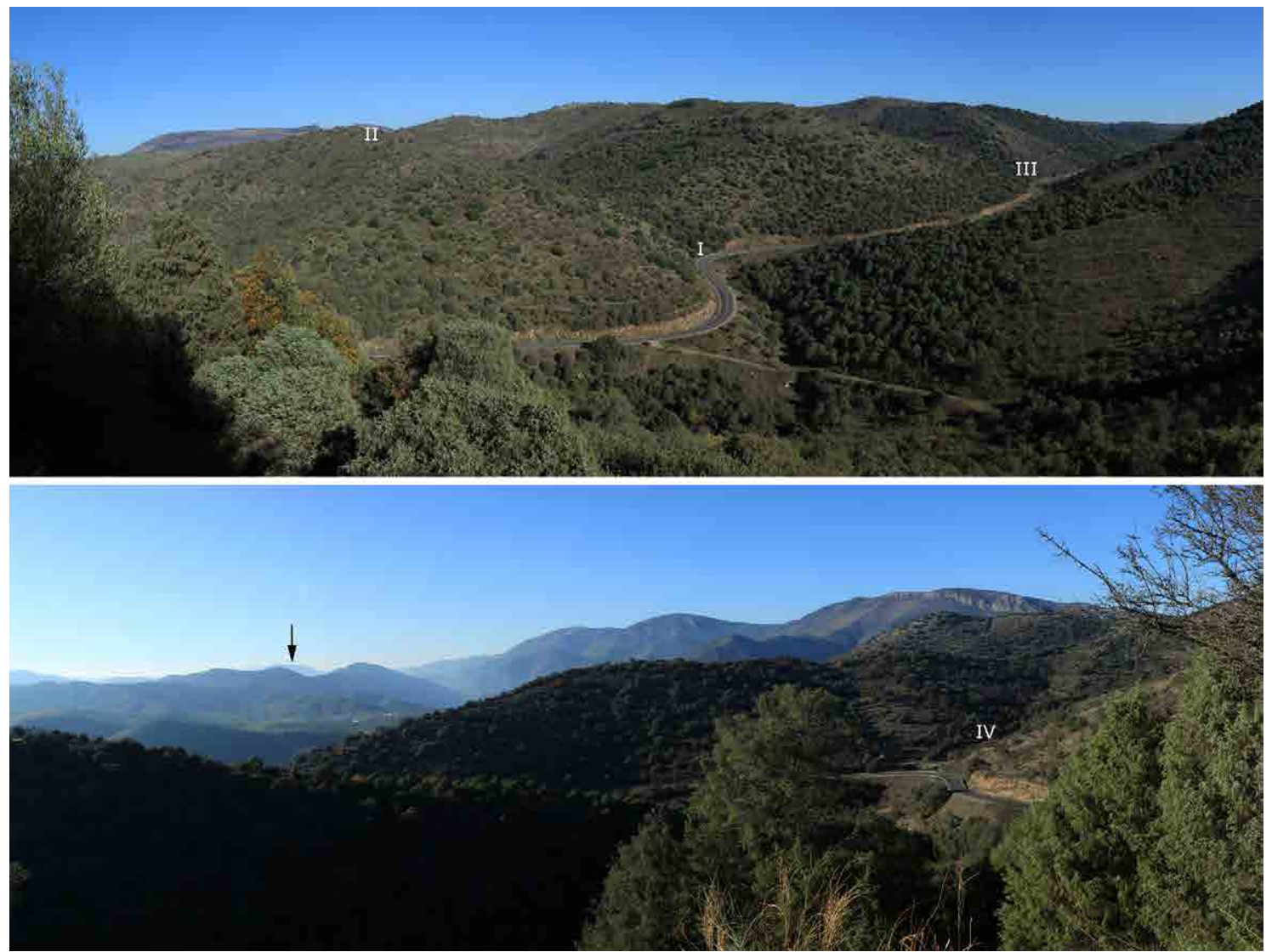

Figura 3. Imágenes de los 4 núcleos con grabados del Arroyo de las Almas. Arriba, las dos principales líneas de agua donde están situados los Núcleos I, II y III. Abajo, en otro afluente, el Núcleo IV. El cerro señalado con la flecha, en el fondo de la imagen, pertenece al sector portugués del valle del Duero, en el inicio del conjunto del arte del Côa.

Estas pizarras y esquistos presentan, mayoritariamente, superficies verticales, tanto de diaclasado como de esquistosidad. Un hecho que también acontece en el conjunto del Côa y en Siega Verde, y que viene determinado por la tectónica regional duriense (Aubry 2009b; Ferreira 1978; Pérez 2011), ya que las fracturas de las diaclasas que se formaron, fundamentalmente en la dirección SSO-NNE (que es también la orientación predominante de la red hídrica regional); de acuerdo con la orientación principal de las líneas de referencia de la falla tectónica, están mayoritariamente orientadas al sudeste o al noroeste. Esta semejanza geológica, que aproxima aún más el conjunto gráfico del Arroyo de las Almas a los cercanos sitios portugueses y a Siega Verde, tiene una excepción en la formación de la rivera principal. Aquí, su orientación general es de tendencia perpendicular a estas líneas de orientación, lo que podría explicar, en parte, la reducida cantidad de afloramientos existentes a lo largo de sus márgenes, limitados a algunos pequeños espacios de las laderas con una orientación más favorable (como sucede en el reducido tramo del Núcleo I sobre el propio Arroyo de las Almas). Por el contrario, los afluentes laterales de la margen derecha siguen la orientación dominante de las fallas tectónicas de la región duriense, favoreciendo así la abundante 
presencia de afloramientos a lo largo de sus amplias laderas.

La gran mayoría de estos afloramientos presentan superficies verticales que se encuentran a la intemperie, aunque también hemos documentado algunos abrigos, más o menos profundos, y dispersos por la margen izquierda del Arroyo de las Almas y en la parte superior del Núcleo II. Si los afloramientos al aire libre tienden a ser simples en la organización de sus superficies verticales ya que no se han documentado grabados en superficies horizontales o cenitales como en Siega Verde (Alcolea y Balbín 2006: 67), con la diaclasa frontal orientada a las riveras y la de esquistosidad lateral perpendicular a las anteriores, los abrigos se tornan más complejos debido a la multiplicación de superficies de esquistosidad, incluyendo el techo y suelo de los abrigos, como ocurre con la roca 1 del Núcleo II (Fig. 4).
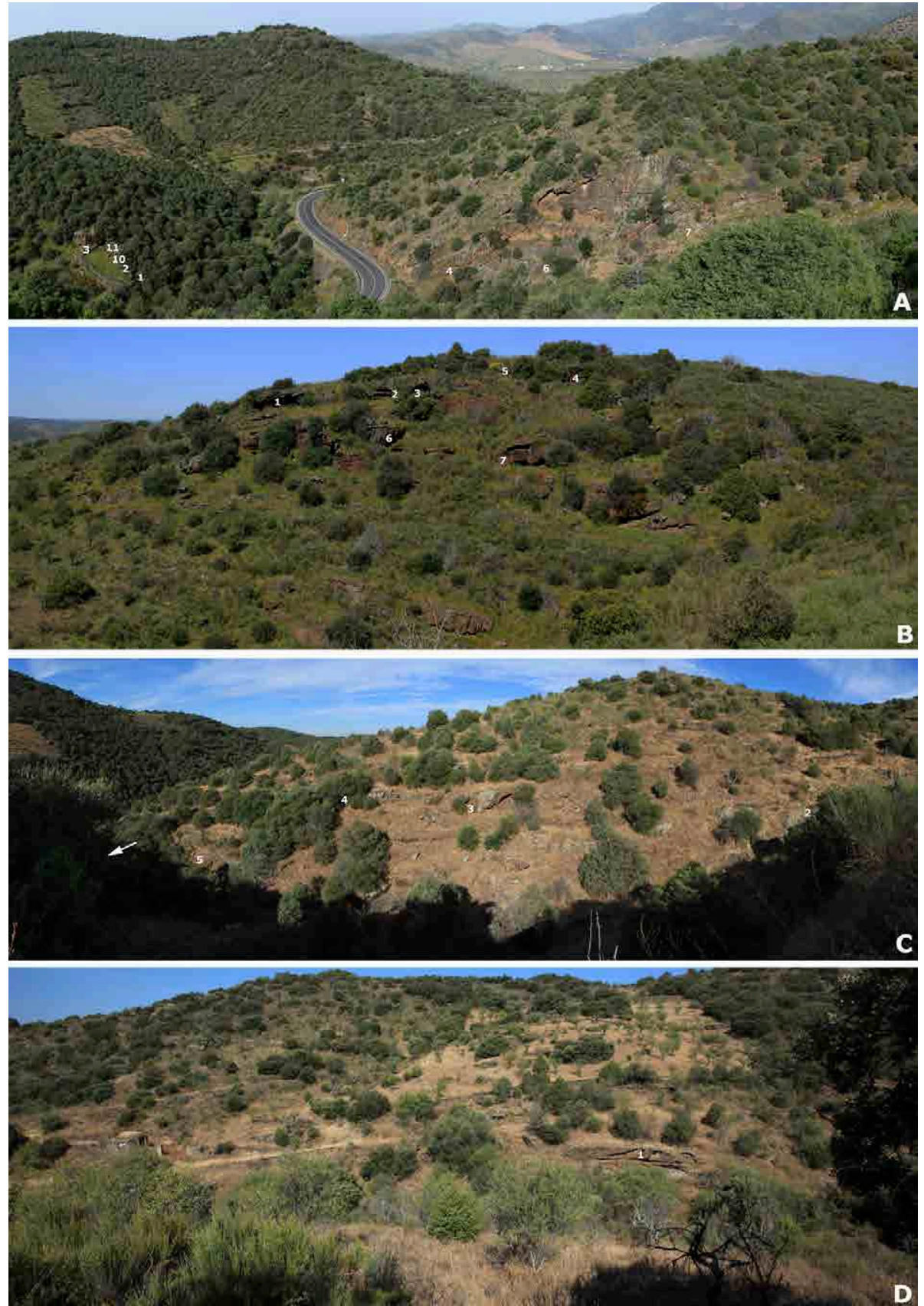

Figura 4. Distribución de las rocas decoradas del Arroyo de las Almas en cada uno de los 4 núcleos. A - Núcleo I (las rocas 5, 8 y 9 no son visibles, a la derecha de la imagen); B - Núcleo II; C - Núcleo III (la flecha indica la posición aproximada de la roca 1, en la margen opuesta a las otras); D - Núcleo IV. 


\subsection{Núcleo I (WGS 84: 41 ${ }^{\circ} 00 ' 55.5 \% \mathrm{~N}$ 654'45.5' W)}

El Núcleo I corresponde al tramo medio y final de una pequeña rivera, que fluye por la margen derecha del Arroyo de las Almas, y a un pequeño tramo del Arroyo. En total fueron aquí inventariadas 11 rocas grabadas con motivos atribuibles tanto al Paleolítico Superior como a la Prehistoria Reciente y al período gráfico más moderno y perteneciente al mundo agropastoril y popular, entre los siglos XVII y XIX (Fig. 4A).

Como ya hemos señalado, las márgenes del Arroyo de las Almas tienen pocos afloramientos al igual que manifestaciones artísticas. La excepción a esta afirmación acontece en el Núcleo I, con 5 rocas grabadas en la orilla izquierda del Arroyo de las Almas (rocas 1, 2, 3, 10 y 11). En este punto, y antes de efectuar un pronunciado giro, surgen las 5 rocas grabadas que se encuentran situadas en la parte final de un amplio y elevado macizo rocoso que se extiende desde el Arroyo a uno de sus afluentes, por su margen derecha, que a su vez está cortado por la carretera CL-517.

En cuanto a este afluente, que nace en la cumbre que hace la separación con las laderas orientadas al Duero, a 440 m. s.n.m., destacar que recorre $1170 \mathrm{~m}$. hasta desembocar en el Arroyo de las Almas, en un recorrido relativamente lineal de nordeste a sudoeste. La primera parte del recorrido se realiza en una zona plana que, sin embargo, pronto inicia un valle profundamente excavado, a $800 \mathrm{~m}$. de la desembocadura. Aquí, este riachuelo pasa por la base de la colina correspondiente al Núcleo II, prosiguiendo su recorrido, en línea recta, hasta el Arroyo de las Almas donde desemboca a 270 m. s.n.m., en un valle que alcanza una profundidad del orden de los $100 \mathrm{~m}$. y que presenta afloramientos a ambos lados: en la parte derecha, en las inmediaciones del arroyo y del gran macizo rocoso final, y en la margen izquierda por toda la ladera, desde las márgenes de la rivera hasta la cima.

A pesar de la existencia de aptas superficies rocosas en la margen izquierda, la prospección que realizamos no nos condujo a ninguna evidencia artística, encontrándose las restantes 6 rocas grabadas del Núcleo I, en la margen derecha y dispersas por el entorno. Las rocas 8 y 9 son las más lejanas, en la base a la colina del Núcleo II, con la roca 8 a una distancia de 440 $\mathrm{m}$. de la desembocadura. La roca 5 surge de forma aislada, y las rocas 4, 6 y 7 aparecen en la base del gran macizo rocoso, cerca de la desembocadura y de las restantes 5 rocas.

Las 11 rocas del Núcleo I se encuentran por tanto cerca de las líneas de agua además de presentar grabados en las superficies de diaclasado, orientadas hacia el sudeste, o en las superficies laterales de esquistosidad, como en algunos paneles de las rocas 1 y 2 .

\subsection{Núcleo II (WGS 84: 4101'12.7'N 6⒌'41.2"'W)}

El Núcleo II ocupa una colina sobre la margen derecha, en la zona media y alta del mismo afluente del Núcleo I, a unos $700 \mathrm{~m}$. aguas arriba de su desembocadura. La cima se localiza a 400 m. s.n.m., estando las 7 rocas decoradas inventariadas en un corto sector de la parte superior de la ladera. La casi totalidad de las rocas grabadas corresponden a abrigos rocosos, generalmente poco profundos y orientados al sudeste; hacia la rivera, excepto en la roca 5 donde los motivos grabados se encuentran en la superficie de diaclasado; al aire libre, y por encima del abrigo (Fig. 4B). En las restantes 6 rocas los grabados se localizan dentro del área abrigada, aprovechando las abundantes superficies disponibles, con orientaciones diversas, por la irregularidad de los abrigos.

Este núcleo tiene, además, el principal conjunto de motivos de la Edad del Hierro, asiduamente mezclados con numerosos motivos de Época Moderna, y un pequeño conjunto de grabados lineales prehistóricos en el suelo del abrigo de la roca 1.

\subsection{Núcleo III (WGS 84: 4100'45.4"N 654'30.0”'W)}

El Núcleo III corresponde a otro pequeño afluente por la orilla derecha del Arroyo de las Almas, cuya desembocadura se localiza a $500 \mathrm{~m}$. aguas arriba de la del afluente del Núcleo I, teniendo características muy similares. Nace entre los montes de La Vinagrera y Fuente de la Hiedra, en la misma cumbre y a la misma altitud, recorriendo, aproximadamente, $1160 \mathrm{~m}$. hasta su encuentro con el Arroyo de las Almas, a 300 m. s.n.m. Su recorrido lineal se desarrolla de nordeste hacia sudeste, correspondiendo los últimos $840 \mathrm{~m}$. a un pequeño valle excavado, con una profundidad máxima de $100 \mathrm{~m}$.

La principal diferencia con otros núcleos grabados radica en la disponibilidad de afloramientos rocosos, escasos y dispersos, aunque con una mayor presencia en el final del regato y junto a sus 
márgenes. De esta forma, las 5 rocas decoradas se concentran en los últimos $200 \mathrm{~m}$. del afluente, siempre cerca de su lecho, al aire libre y con manifestaciones artísticas en la superficie vertical de diaclasado orientadas al arroyo (Fig. 4C).

La roca 4 es la única que también tiene grabados en una superficie lateral de esquistosidad. La roca 1 , que se encuentra en la margen izquierda, se orienta al noroeste, estando las restantes rocas en el margen opuesto y orientadas al sudeste.

Para concluir con el Núcleo III, destacar los grabados del Paleolítico Superior en la roca 3 (Vázquez Marcos y Reis 2019: 143), y su importante conjunto de motivos de la Edad del Hierro, quizá menos exuberantes que las evidencias documentadas en algunos de los abrigos del Núcleo II.

\subsection{Núcleo IV (WGS 84: 4101'13.4'N $6^{\circ} 54^{\prime} 59.7^{\prime} \mathrm{W}$ )}

El Núcleo IV se localiza en torno a un pequeño afluente del Arroyo de las Almas, nacido en la misma cumbre, entre el teso Cabeza de Cántaro y el de Colmenar, muy cerca del despoblado de San Martín y con una similar longitud a los previamente referidos. En esta ocasión su desembocadura se sitúa a unos $850 \mathrm{~m}$. de distancia, aguas abajo, del afluente del Núcleo I, a 210 m. s.n.m. y a menos de $2 \mathrm{~km}$. del río Águeda. Su principal diferencia radica en la existencia de otra rivera con la que se reúne, $200 \mathrm{~m}$. antes de encontrarse con el Arroyo de las Almas. Sin embargo, este hecho no tiene consecuencias para el arte rupestre, pues los cursos superiores de estas dos, están prácticamente vacíos de afloramientos rocosos. De hecho, a $180 \mathrm{~m}$. de distancia del Arroyo de las Almas y después de la unión de las dos riveras, se encuentra un gran afloramiento, en la margen derecha y sobre su lecho. Se trata de un imponente y elevado abrigo, aunque poco profundo, orientado a la rivera (Fig. 4D). La superficie vertical de diaclasado se divide en diversos paneles, 7 de los cuales presentan gran cantidad de grabados, sobre todo del $\mathrm{Pa}$ leolítico Superior y la Prehistoria Reciente, además de un motivo geométrico moderno.

\section{El arte rupestre en el Arroyo de las Almas: una visión general}

Como ya hemos mencionado en la introducción, durante la prospección arqueológica realizada entre septiembre de 2015 y los últimos días de 2016, cuando terminamos el trabajo de campo, 24 fueron las rocas decoradas descubiertas, en 4 núcleos gráficos. En total, conseguimos inventariar más de 600 motivos, un resultado final que estará por debajo de la realidad, teniendo en cuenta la gran dificultad que hemos encontrado para discernir algunas de estas figuras, ya sea por su extremo desgaste o por las densas superposiciones que en algunas ocasiones vuelven muy problemática su correcta clasificación. Estos motivos han sido agrupados en cuatro grandes períodos cronológicos: Paleolítico Superior, Prehistoria Reciente, Edad del Hierro y Época Moderna y Contemporánea.

De igual modo, queremos recalcar que la técnica mayormente documentada para la ejecución de las figuras es la incisión, principalmente en trazos finos y únicos, aún habiéndose observado y catalogado otras modalidades técnicas como el trazo múltiple. Sólo en la Prehistoria Reciente existe una destacable variedad técnica, con un pequeño conjunto de motivos figurativos piqueteados, en el Núcleo I, además de una relevante presencia de grabados lineales obtenidos por abrasión, muchas veces asociadas a otros trazos incisos, en los Núcleos II y IV.

Finalmente, reseñar las pequeñas dimensiones de la mayoría de las figuras inventariadas, con las mayores infrecuentemente superiores a los $30 \mathrm{~cm}$. de longitud máxima, teniendo las más pequeñas dimensiones que se aproximan, o son inferiores, a los $5 \mathrm{~cm}$. de longitud máxima.

\subsection{Paleolítico Superior}

Es el período que presenta el menor número de figuras, habiendo conseguido estudiar en detalle las 5 rocas con motivos atribuibles a dicho momento. Son 21 las unidades que hemos inventariado, de las cuales 13 son motivos zoomorfos y 7 pertenecen a la categoría temática de los signos, además de un motivo indeterminado documentado en la roca 11, cuya interpretación y asignación cronológica resulta cuanto menos complicada.

Salvo error, las rocas 6 y 7 del Núcleo I y la roca 3 del Núcleo III no deberían tener más novedades gráficas. Esto mismo no podemos asegurarlo al respecto de la roca 1 del Núcleo IV, donde las figuras paleolíticas, de reducidas dimensiones y muy patinadas, se mezclan con grabados lineales postglaciares ejecutados tan- 
to por abrasión como por incisión, además de superponerse en numerosos casos a las manifestaciones anteriores y desdibujar su distinción. Así, y teniendo en cuenta las dificultades para observar las zonas más elevadas de los paneles decorados de esta roca, por encima de los $2 \mathrm{~m}$. de altura, y donde detectamos algunos trazos grabados, es posible que pueda tener uno u otro motivo más, aún por identificar.

Por otro lado, y más allá de los signos, las 5 rocas paleolíticas presentan diversas cantidades de trazos sueltos, de caótica apariencia y organización, y que no hemos contabilizado como figuras.
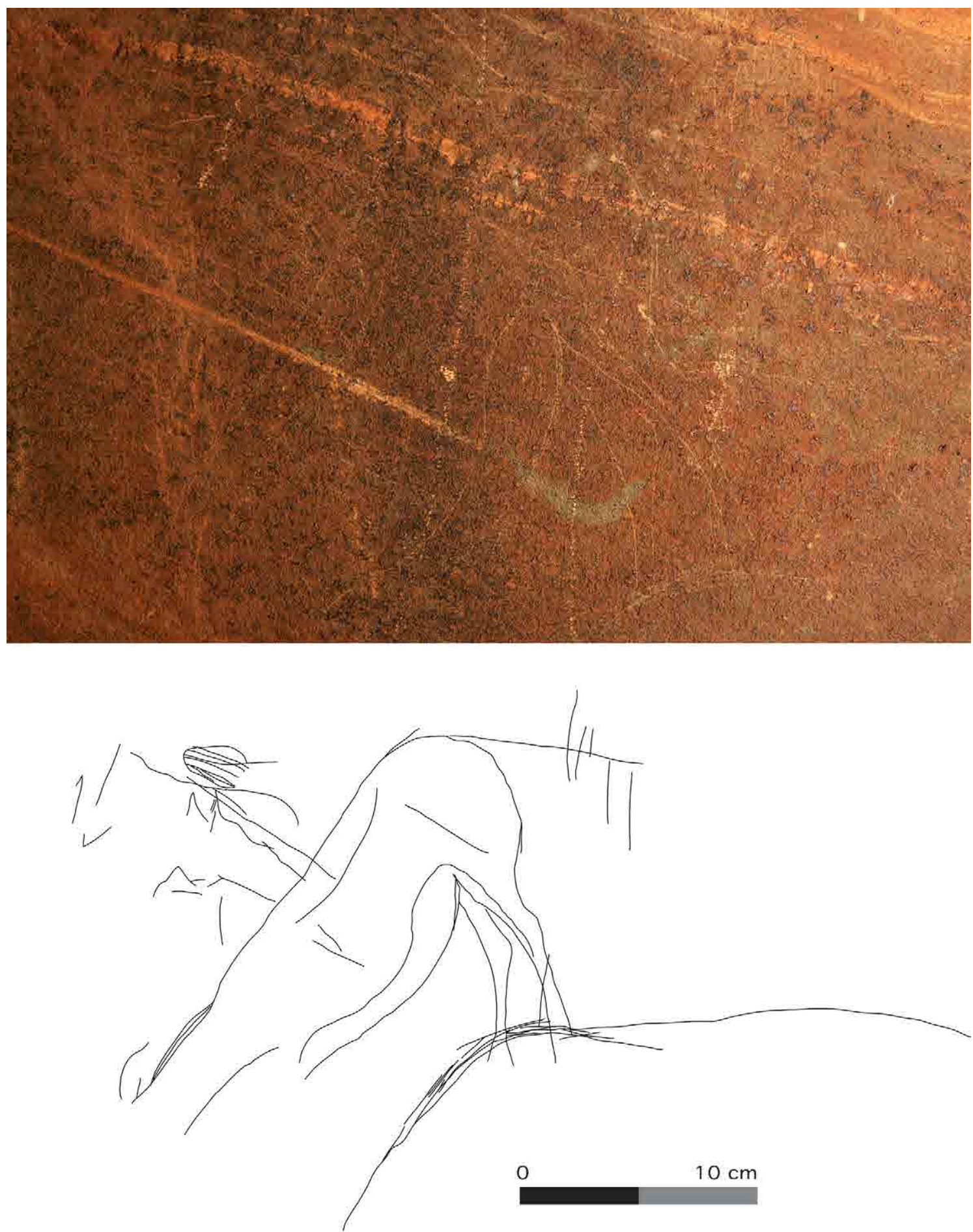

Figura 5. Posible cierva, de cronología Magdaleniense, en el panel 2 de la roca 3 del Núcleo III. 
Los animales localizados pertenecen a tres especies: 6 ejemplares de cérvidos, 4 de équidos y 2 caprinos, además del cuadrúpedo indeterminado en el Núcleo IV, que quizá podría ser incluido como un équido más. En las rocas 6 y 7 del Núcleo I y en la roca 3 del Núcleo III hemos reconocido una única representación zoomorfa, asociada a 3 signos.

Sin lugar a duda, la roca más sensacional está en el Núcleo IV, con 14 figuras, ya que congrega la gran mayoría de las representaciones zoomorfas, 10 en total. Las dimensiones de estas figuras oscilan entre los 2,5 $\mathrm{cm}$. del prótomo de un cérvido y los $25 \mathrm{~cm}$. del cuadrúpedo indefinido, ambos en la roca
1 del Núcleo IV. Junto a algunas de estas, sobresalen, desde el punto de vista estético, el magnífico ciervo de la roca 6 del Núcleo I (Vázquez Marcos y Reis 2019: 140 y 143), y el ya señalado animal acéfalo colocado en vertical, probablemente un cérvido, con un despiece ventral, en la roca 3 del Núcleo III (Fig. 5).

En la roca 1 del Núcleo IV también debemos resaltar la cierva del panel 6 y la sucesión de 6 animales en el último de sus 7 paneles, con una secuencia de 3 prótomos de équidos, asociados a otro zoomorfo de la misma especie, aunque de menores dimensiones e incompleto, y al cuadrúpedo indeterminado.
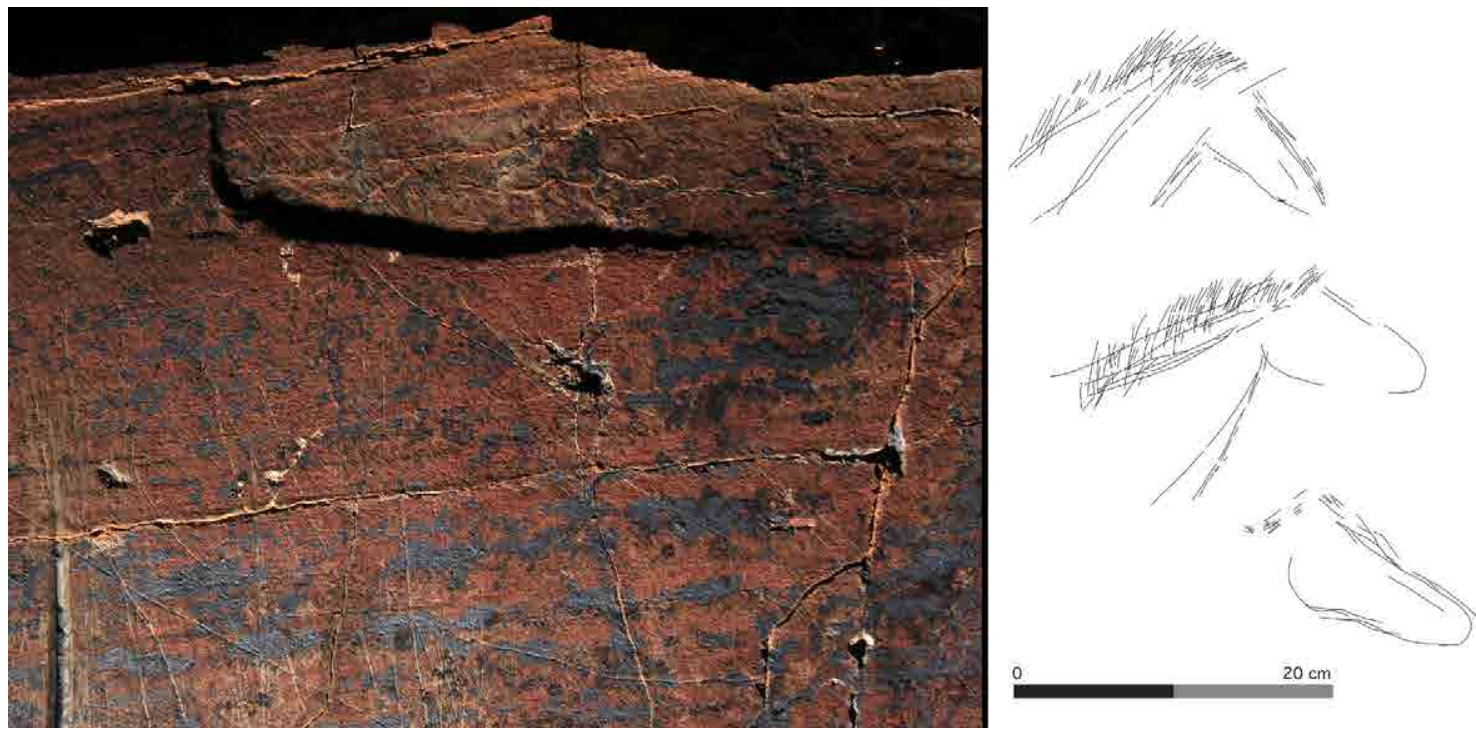

Figura 6. Prótomos de équido del panel 7 de la roca 1 del Núcleo IV. A la izquierda, fotografía del situado en posición inferior en el calco de la derecha.

Desde el punto de vista cronológico todas estas figuras se encuadran en el Magdaleniense, pudiendo, en el caso de los 3 prótomos de équido, retroceder eventualmente al Solutrense Final (Fig. 6). Asimismo, hemos reconocido un pequeño conjunto de figuras zoomorfas con una defendible asignación cronocultural dentro del final del ciclo artístico o gráfico Paleolítico, que se desarrolla entre la segunda mitad del Tardiglaciar y el Holoceno temprano $(\sim 12,000-9,000 \mathrm{BP}) \mathrm{y}$ que, de igual manera, han sido documentadas en el contexto arqueológico más inmediato del Côa y Siega Verde, además de en otros enclaves peninsulares más alejados (Aubry et al. 2017; Bueno et al. 2008; Bueno y Balbín 2016; Corchón et al. 1996: 41-46; García Diez y Cacho 2015; Reis 2014; Steelman et al. 2017: 160-161) o euroasiáticos (D'Errico 1994; Maida et al. 2018). Estos zoomorfos serían, al menos, los caprinos de la roca 7 del Núcleo I y de la roca 1 del Núcleo IV, grabados ambos por incisión en trazo múltiple y repetido (Fig. 7). 

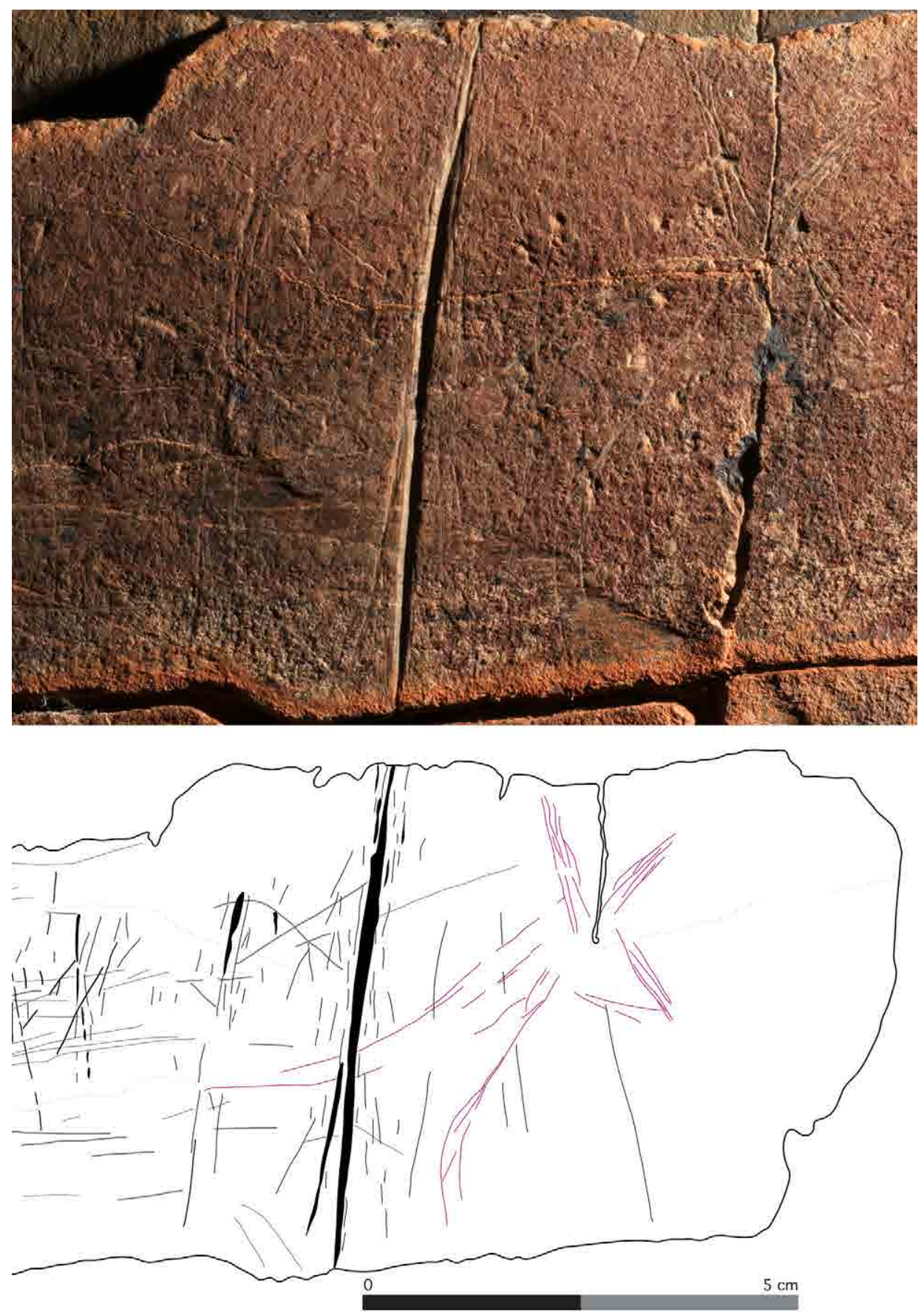

Figura 7. Caprino del panel 6 de la roca 1 del Núcleo IV, superpuesto por un grabado lineal del tipo "uñada del diablo".

\subsection{Prehistoria Reciente}

La Prehistoria Reciente está representada en Arroyo de las Almas en 3 de sus 24 rocas (entendemos por Prehistoria Reciente el largo período que transcurre entre el final del Paleolítico Superior y el principio de la Edad del Hierro). Éstas, se encuentran dispersas a lo largo del conjunto, correspondiendo, cada una, a la primera roca de un núcleo diferente: Núcleos I, II y IV.

En el primer gran panel de la roca 1 del Núcleo I descubrimos 2 figuras de este período. Ejecutadas ambas por la técnica de grabado piqueteado, pertenecen al universo del arte 
esquemático, como reflejan sus principales características técnicas, temáticas y morfoestilísticas, con irrefutables paralelos con las de otros parajes cercanos del territorio portugués (Baptista y Reis 2008: 180; Garcês 2017: 142) y español (Collado 2008: 315).

Se localizan en el centro del panel. Son un antropomorfo (Fig. 8) y una peculiar figura zoomorfa incompleta y de difícil interpretación. Durante algún tiempo pasaron desapercibidas, puesto que no destacan en el panel ni se distinguen fácilmente del enmarañado de figuras añadidas posteriormente por las sociedades agro-pastoriles, entre los siglos XVII y XIX, muchas de las cuales se encuentran superpuestas.
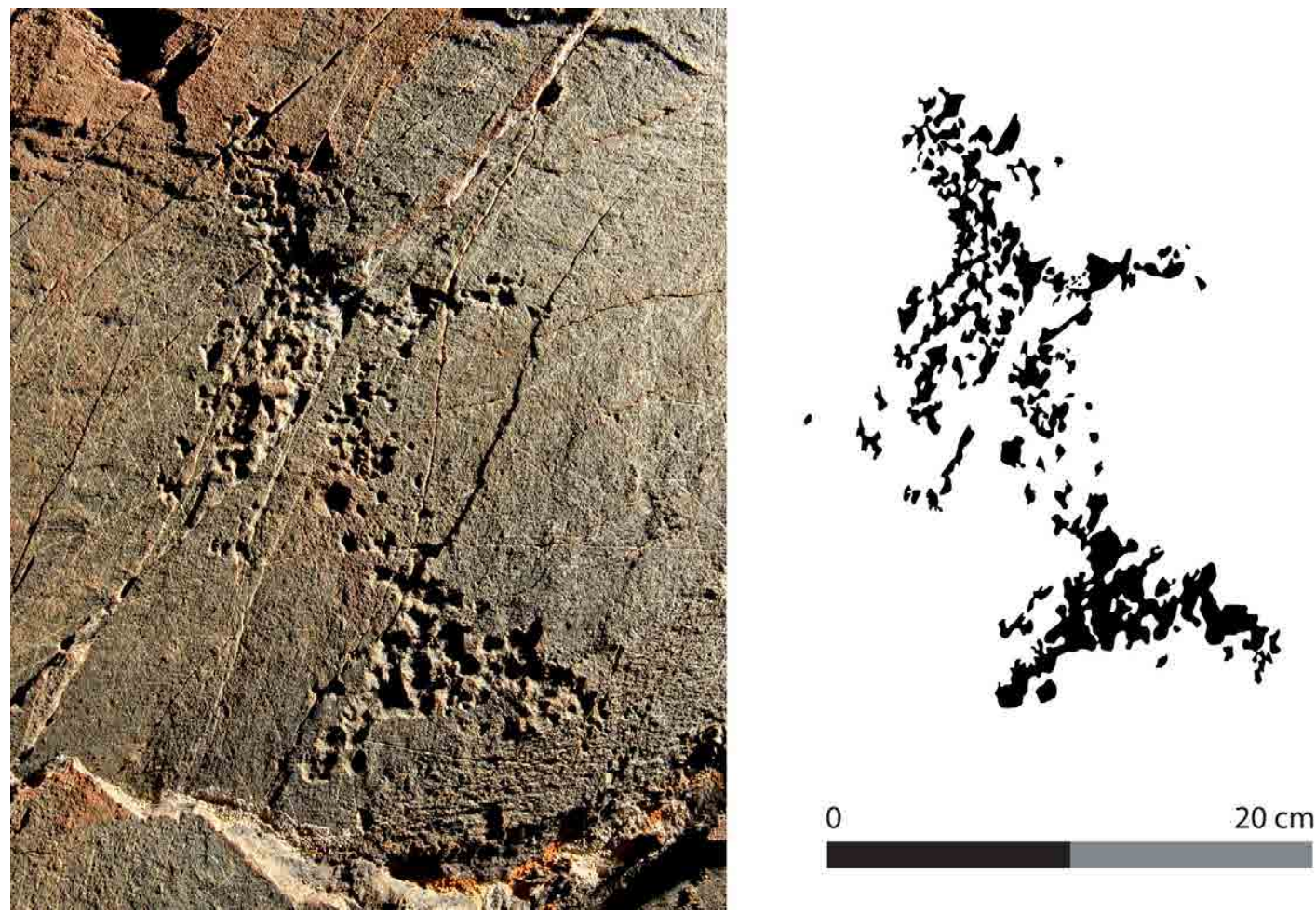

Figura 8. Antropomorfo esquemático piqueteado de la Prehistoria Reciente, en el panel 1 de la roca 1 del Núcleo I del Arroyo de las Almas.

En los Núcleos II y IV también se localizaron representaciones de este mismo momento cronocultural. En este caso, un amplio conjunto de figuras lineales profundamente grabadas por abrasión e incisión, a las que llamamos "uñadas del diablo" (Fig. 9).

Hemos adoptado esta nomenclatura ya que así es como se designa a este tipo de grabados, popular y científicamente, en el noreste de Portugal, donde su presencia está ampliamente inventariada, aunque grabados lineales, de distintas cronologías y orígenes culturales, se conozcan a lo largo de todo el territorio ibérico. En un próximo trabajo profundizaremos sobre estas peculiares representaciones fusiformes y las hipótesis planteadas sobre su cronología y funcionalidad. Sobre el primer aspecto, su cronología, que aún continúa siendo discutida (Reis 2014: 43-47; Teixeira y Sanches 2017), señalar que la hipótesis que aquí defendemos es aquella que las sitúa en la Prehistoria Reciente. La designación "uñadas del diablo" se aplica así a un grupo marcadamente regional de grabados lineales y localizadas, sobre todo, a lo largo de la cuenca del Duero portugués, formando un grupo muy homogéneo gracias a sus principales características: la modalidad técnica de grabado, sus dimensiones, la apariencia visual y perceptibilidad, la geología utilizada (siempre esquistos y pizarras) y su implantación en el paisaje.

Debemos añadir asimismo, que estas 2 rocas del Arroyo de las Almas son las primeras con este particular tipo de representación que se han identificado e interpretado como tal en la cuenca española del Duero ya que, al contrario de lo que afirmamos anteriormente tras ser descubiertas (Reis y Vázquez Marcos 2015: 
40), los grabados lineales de la roca de Vilvestre (Salamanca) (Benito del Rey et al. 1970) difícilmente se podrán encuadrar en este grupo descrito.

Como veremos en el siguiente apartado con más detalle, la roca 1 del Núcleo II es una de las más notorias del conjunto de Arroyo de las Almas, por sus excelentes representaciones de la Edad del Hierro. Sin embargo, las "uñadas del diablo" también están presentes en el suelo del abrigo, conformando un pequeño conjunto de 4 unidades, abrasionadas y acompañadas de varios trazos incisos.

Es, empero, en la roca 1 del Núcleo IV, donde son más abundantes, ya que han sido catalogados en 6 de los 7 paneles decorados de esta roca. Aquí, hemos contabilizado 130 "uñadas" profundamente abrasionadas, casi siempre acompañadas por abundantes trazos incisos.
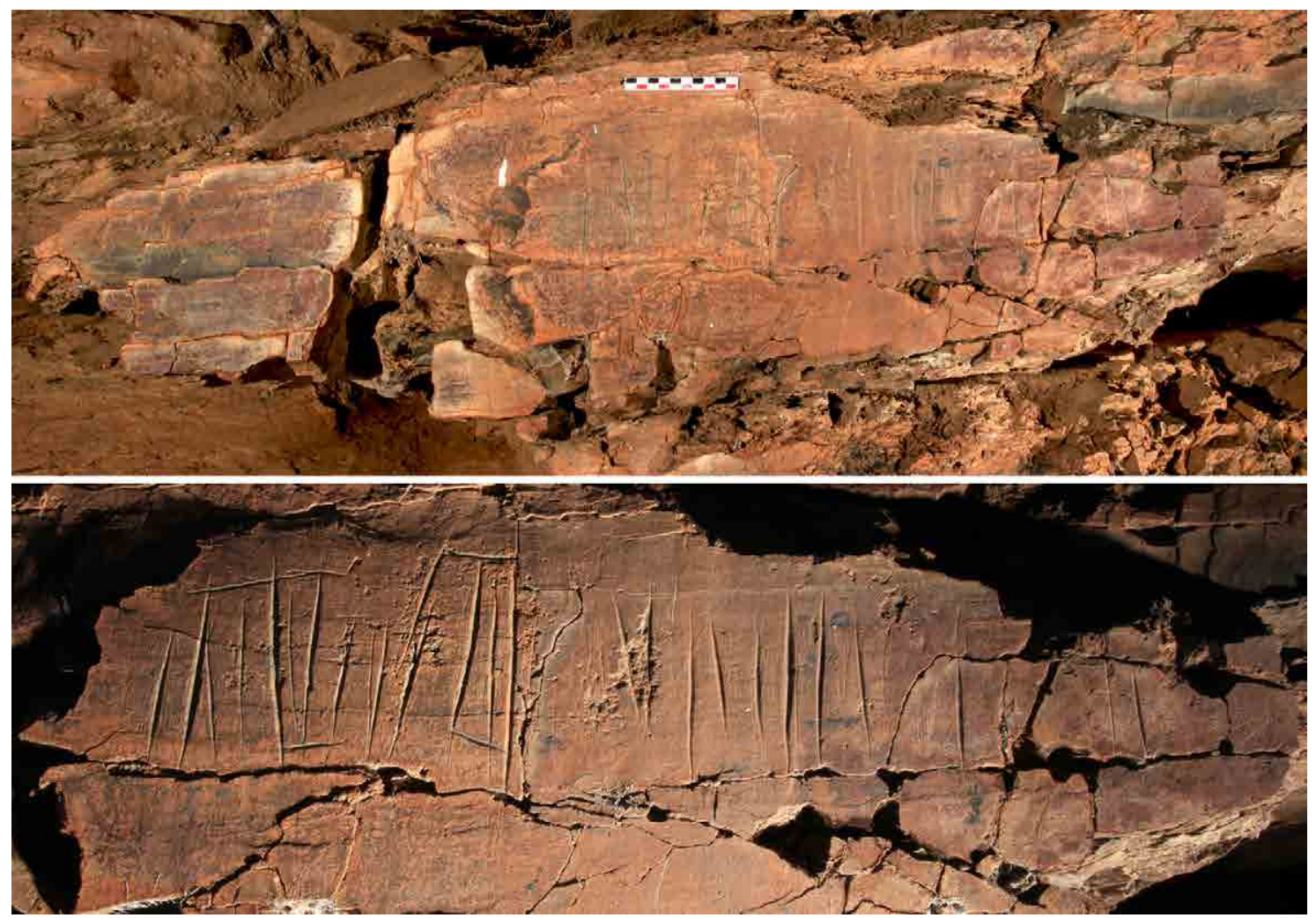

Figura 9. Panel 6 de la roca 1 del Núcleo IV, con grabados lineales del tipo "uñadas del diablo", ejecutadas por abrasión e incisión. Se superponen a algunos conjuntos de piqueteados, aparentemente informes y a varias pequeñas figuras paleolíticas, no discernibles en las imágenes presentadas.

Abajo, detalle del principal conjunto de grabados lineales.

\subsection{Edad del Hierro}

Tras contabilizar más de 120 motivos de la Edad del Hierro, podemos afirmar que el Arroyo de las Almas es uno de los más destacables conjuntos con arte rupestre de este período, en la cuenca del Duero, siendo estos motivos mayoritariamente abstractos, aunque también hemos detectado una importante presencia de zoomorfos, contrastando con las exiguas representaciones humanas. Estas figuras están localizadas en 11 de las 24 rocas catalogadas,
6 en el Núcleo II y 5 en el Núcleo III. Además, en ambos núcleos, las rocas con grabados; técnica sustractiva mayoritaria para la ejecución del arte protohistórico peninsular y europeo (Royo Guillén 2005: 158), se sitúan de forma sucesiva, muy próximas unas de las otras y, en Arroyo de las Almas, exclusivamente en la variante incisa.

El Núcleo III tiene, al menos, 50 motivos. En las rocas 1, 2, 3 y 5 no son más que 2 los motivos figurativos zoomorfos, un animal indeterminado aparentemente acéfalo en la roca 
1 y un pequeño ciervo, que no supera los 10 $\mathrm{cm}$ de longitud máxima y decorado en su interior, en la roca 3. El resto de los grabados documentados en estas 4 rocas son de naturaleza abstracta. La roca 4 , por el contrario, presenta numerosas figuras distribuidas en 7 paneles decorados. La mayoría consiste en motivos abstractos, como en el panel 6 , con numerosos reticulados, zigzags y conjuntos de trazos paralelos, aunque en el panel 2, claramente desemejante y mucho más relevante para el sitio, destaca una pareja de jinetes, acompañados de un gran ciervo con rectos cuernos ramificados y varios signos. Si bien los primeros están representados con pocos detalles anatómicos, hemos de subrayar que uno de los caballeros parece sostener riendas, mientras que el otro maneja una posible lanza (Fig. 10). Además, y pese a su compleja interpretación, consideramos que podría tratarse de una escena de caza, con paralelos iconográficos con algunos de los más relevantes enclaves cercanos ya sea en la región del Côa (Vale da Casa, Vermelhosa o Foz do Côa, entre otros) (Luís 2015: 95 y 97; Reis 2014: 52$54)$, en los yacimientos fortificados salmantinos (Yecla de Yeltes o Las Merchanas) (Martín Valls y Carnicero 2008; Vázquez Marcos 2010), hurdanos (Sevillano 1991), o en otros más alejados como los del Guadiana (Collado y García 2007), la costa mediterránea (Royo Guillén 2005: 178) o la fachada Atlántica (Chan de Lagoa 2 o Laxe de Sartaña, entre otros) (Santos Estévez 2008: 57 y 74).
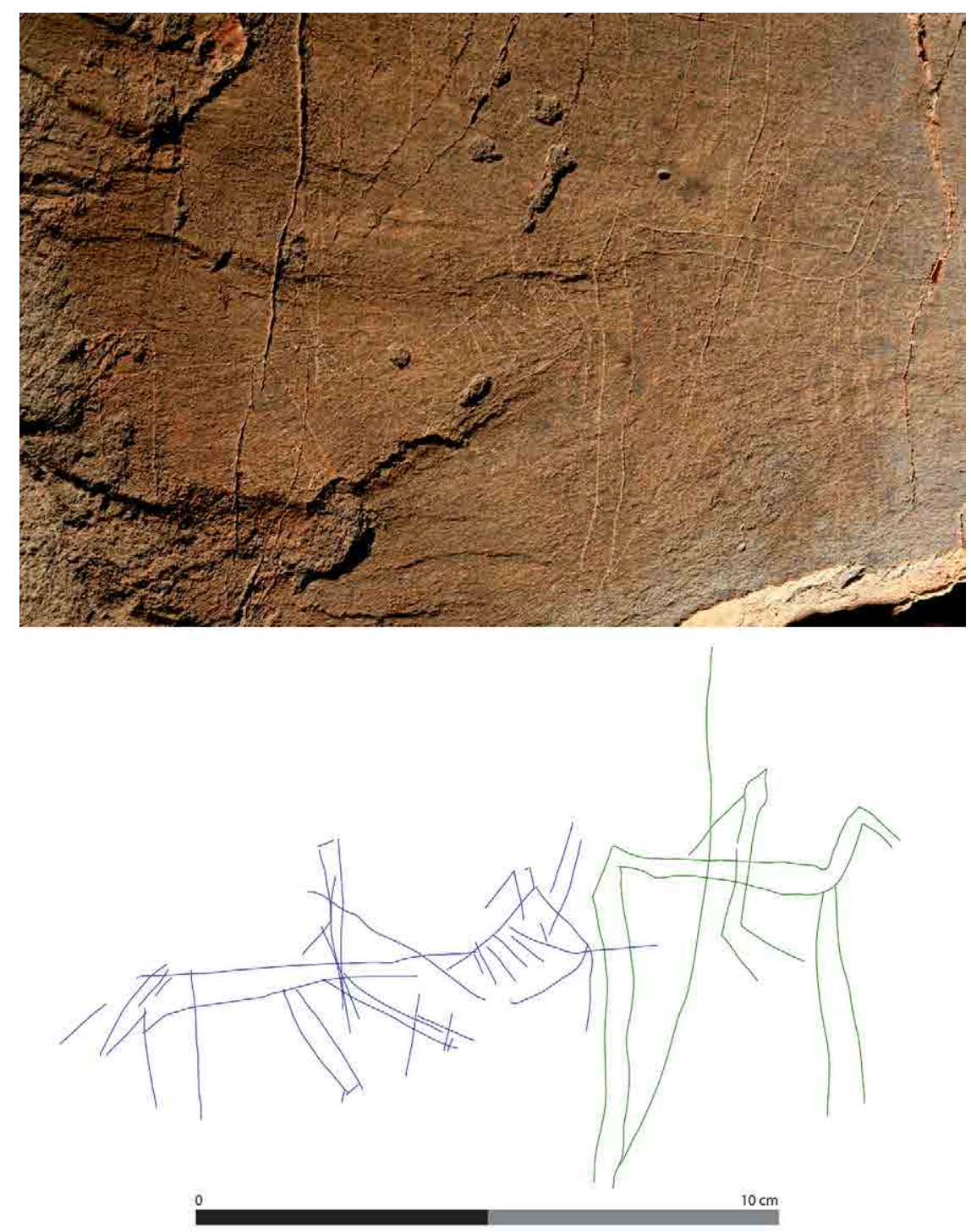

Figura 10. Caballeros de la Edad del Hierro en el panel 2 de la roca 4 del Núcleo III del Arroyo de las Almas. 
El Núcleo II tiene en sus 6 rocas decoradas de la Edad del Hierro más de 60 motivos. La mayoría de las rocas tienen una reducida cantidad de grabados, casi siempre de carácter abstracto, destacando, además, varias representaciones de animales, en particular los de las rocas 2, 4, 5 y 6 , aislados, como en la roca 5 , o en compañía de figuras abstractas con diferentes tipologías.

Es la roca 1, con 22 paneles decorados, 16 de los cuales tienen motivos de la Edad del Hierro, la más importante (Fig. 11). En ella, hemos identificado, en el interior del abrigo, algunas zonas con una nada desdeñable acumulación de sedimentos, donde identificamos cerámicas de fabricación manual que, pese a la ausencia de decoraciones y elementos tipológicos más seguros, podrían adscribirse a la Edad del Hierro, pudiendo proporcionar un importante contexto arqueológico para este conjunto de grabados. Un desafío para quien pueda estar interesado en investigar este aspecto más a fondo.
En cuanto a su repertorio iconográfico compuesto por casi 50 motivos, destacar tanto la única figura antropomorfa del panel 3, una peculiar representación vista de frente con los brazos abiertos, como la decena de figuras de animales, casi todos ciervos, con varias e imponentes representaciones como la de los paneles 8 y 3 , aunque en este último caso mutilada por una fractura en el panel. Los demás motivos son todos de carácter abstracto, con una gran variedad tipológica y complejidad gráfica.

Para terminar, señalar que ambos conjuntos de rocas siguen un patrón similar: una roca que congrega gran cantidad y variedad de figuras, incluyendo los únicos antropomorfos del conjunto grabado de este período, rodeadas de otras rocas con pocos motivos y una menor variedad tipológica. Esta pauta es muy similar al que se encuentra en muchos de los sitios de la Edad del Hierro de la región del Côa, reforzando las evidentes relaciones entre los sitios portugueses y el Arroyo de las Almas (Reis 2014: 53).
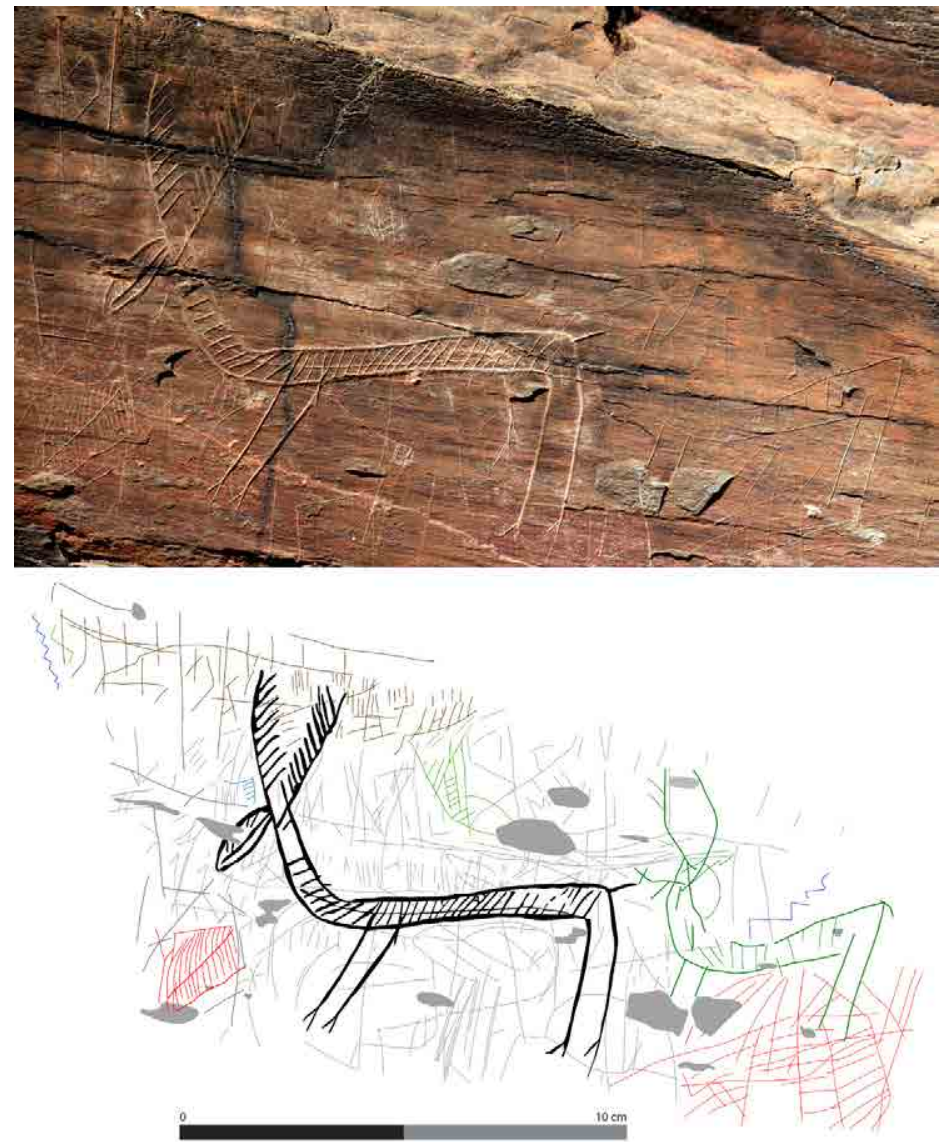

Figura 11. Parte del panel 8 de la roca 1 del Núcleo II del Arroyo de las Almas con varias figuras incisas de la Edad del Hierro, entre ellas un espléndido y majestuoso ciervo. 


\section{4. Época Moderna}

Las representaciones más recientes del Arroyo de las Almas son también las más abundantes, al haberse contabilizado cerca de 300 motivos, la mitad del repertorio gráfico del conjunto. Su presencia se ha documentado en 16 de las 24 rocas, siendo muy significativa en los Núcleos I y II y más modesta y exigua en los Núcleo III y IV.

En el Núcleo II los grabados incisos de este período se encuentran en todas sus rocas, con la salvedad de la 5 y 7 , siendo las rocas 1 y 4 las más relevantes, y donde los motivos modernos se mezclan con otros de la Edad del Hierro, de los cuales, a veces, resulta complejo diferenciarlos al haber sido ejecutados con la misma modalidad técnica y tener una pátina muy semejante.
De entre las principales categorías temáticas observadas queremos reseñar el predominio de los motivos abstractos, con numerosos reticulados y algunos pentalfas, aunque también se han detectado figuras zoomorfas, como ciervos, aves; preferentemente gallináceas de pequeñas dimensiones y pormenorizados detalles como tarsos con dedos y múltiples coberteras, al igual que representaciones de otros posibles animales domésticos (carneros) o silvestres (ciervos) y armas (lanzas y ballestas), como en el panel 3 de la roca 1, con una posible escena de cariz venatorio.

En el Núcleo I los motivos son muy similares a los del Núcleo II, aunque mucho más abundantes y esplendentes, congregando el panel 1 de la roca 1 más de la mitad del total de los catalogados para este período.
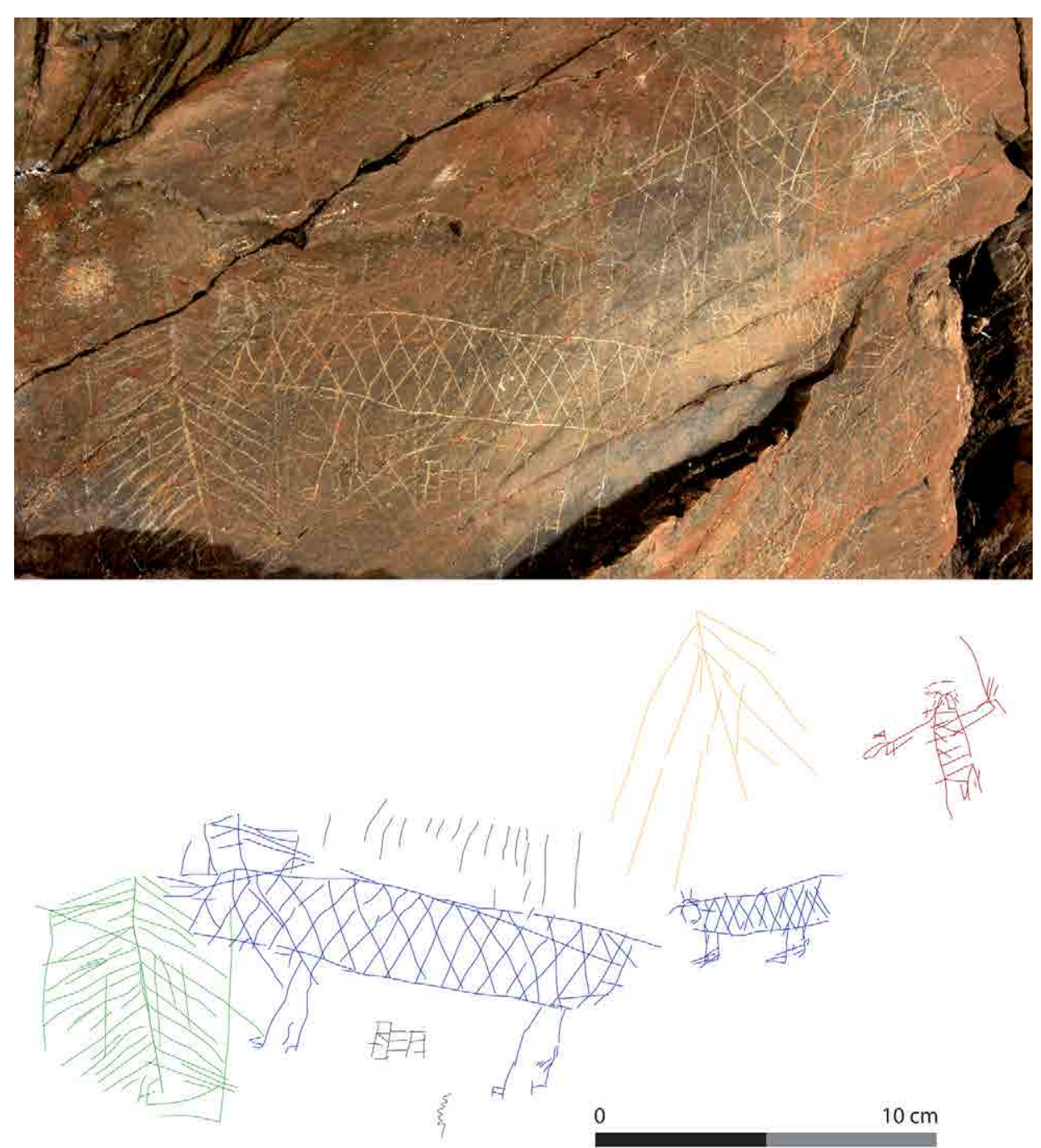

Figura 12. Pequeño grupo de figuras, incluyendo representaciones humanas, animales y abstractas, de entre los incontables motivos de Época Moderna del panel 1 de la roca 1 del Núcleo I del Arroyo de las Almas. 
Las figuras de esta fase cronocultural se extienden por todo el núcleo y en casi todas las rocas, con las únicas excepciones de las rocas 7 y 11 , y con el predominio de la categoría abstracta, de una gran variedad tipológica y calidad estética, como los numerosos reticuladas de los cuales destaca la colección de la roca 5. Otras tipologías son más raras, casi siempre asociadas a estos motivos, como un antropomorfo acompañado de un ciervo y un pentalfa en la roca 9 , un cruciforme en la roca 5 o un posible caprino en la roca 4. Este último tiene grandes semejanzas con algunos de los motivos zoomorfos inventariados en la parte inferior del Núcleo I, más concretamente en las rocas $1,2,3$ y 10 , que están agrupadas en un amplio macizo rocoso en la margen izquierda del Arroyo de las Almas, dentro de una antigua construcción pastoril rodeada por un gran corral y chivitera, con la que debe estar relacionado, y donde se encuentra la roca 3 , sirviendo de pared de fondo.

Sin embargo, es la roca 1 la más importante de este período agro-pastoril y popular, con más de 150 motivos y un panorama gráfico muy semejante al del resto del núcleo (Fig. 12), con el predominio absoluto de motivos abstractos, de una gran variedad tipológica, acompañados de algunos animales, pentalfas y figuras humanas, restringidas al panel 1 de esta espléndida roca.

El predominio de las figuras abstractas y la escasez de motivos antropomorfos y zoomorfos es resaltable, aunque todavía lo es más la casi ausencia de motivos religiosos cristianos (aunque hallamos inventariado varios pentalfas), inscripciones, rúbricas o fechas, reducidas únicamente a 4 unidades claras. No tenemos datos fehacientes por tanto, que permitan circunscribir con mayor seguridad la cronología de este conjunto de figuras modernas, que excepto en algunos grupos de caóticos trazos y de pátina muy reciente, resultan bastante homogéneos y de una relativa antigüedad. Pese a esto, y aunque sea difícil sugerir cronologías más precisas, proponemos los siglos XVII y XVIII para su ejecución, no siendo imposible que algunas puedan ser aún más antiguas, y que otras figuras puedan pertenecer al siglo XIX, como ya hemos comprobado en otros enclaves de la comarca salmantina de Ciudad Rodrigo (Vázquez Marcos y Angulo Cuesta 2019: 65 y 66).

Tabla 1. Relación cronológica de los motivos figurativos y abstractos del conjunto rupestre de Arroyo de las Almas.

\begin{tabular}{|c|c|c|c|c|c|}
\hline Núcleo & Roca & Paleolítico Superior & Prehistoria Reciente & Edad del Hierro & Época Moderna \\
\hline I & 1 & - & 2 & - & 183 \\
\hline I & 2 & - & - & - & 18 \\
\hline I & 3 & - & - & - & 20 \\
\hline I & 4 & - & - & - & 1 \\
\hline I & 5 & - & - & - & 2 \\
\hline I & 6 & 1 & - & - & - \\
\hline I & 7 & 1 & - & - & 9 \\
\hline I & 8 & - & - & - & 24 \\
\hline I & 9 & - & - & - & 3 \\
\hline I & 10 & - & - & - & - \\
\hline I & 11 & 1 & - & 46 & 40 \\
\hline II & 1 & - & 4 & 4 & 2 \\
\hline II & 2 & - & - & - & 13 \\
\hline II & 3 & - & - & 8 & - \\
\hline II & 4 & - & - & 1 & - \\
\hline II & 5 & - & - & 4 & - \\
\hline II & 6 & - & - & 1 & - \\
\hline II & 7 & - & - & 2 & - \\
\hline III & 1 & - & - & 6 & - \\
\hline III & 2 & - & - & 1 & - \\
\hline III & 3 & 4 & - & 41 & - \\
\hline III & 4 & - & - & - & 1 \\
\hline III & 5 & - & 131 & & \\
\hline IV & 1 & 14 & & & \\
\hline
\end{tabular}




\section{Consideraciones finales}

Para concluir con este estimable y numeroso conjunto artístico del Arroyo de las Almas, con más de 600 motivos ejecutados en diferentes períodos cronoculturales, además de variado en sus temas y técnicas de grabado, y tras una primera descripción y análisis de los datos recopilados a lo largo de los dos últimos años, queremos plantear, a modo de consideraciones finales, las siguientes cuestiones, hipótesis e interrogantes surgidos tras nuestro trabajo:

1. El descubrimiento de este conjunto arqueológico amplía el ya de por sí numeroso arte rupestre superopaleolítico en la cuenca del Duero internacional, convirtiéndose, tras Siega Verde, aunque de un forma más limitada y modesta al haberse inventariado únicamente 21 figuras seguras (Vázquez Marcos y Reis 2019: 141-142), en el más relevante de la provincia de Salamanca y en uno de los más importantes de la comunidad autónoma en la que se integra. De igual forma, el descubrimiento de este paraje rupestre, con 24 rocas grabadas, nos muestra la importancia de los trabajos prospectivos largamente subestimados, al ser considerados como una actividad arqueológica "menor" (Ruiz Zapatero 1996: 14), aunque indispensable, a nuestro entender, para el conocimiento del fenómeno artístico y de las sociedades prehistóricas que lo realizaron, y que tantos resultados positivos están suministrado en el territorio portugués (Baptista 2009, 2012; Figueiredo et al. 2014, 2016; Reis 2011, 2012, 2013, 2014; Santos et al. 2015; Teixeira y Sanches 2017).

2. Con respecto a los temas grabados más antiguos del conjunto, queremos insistir en que todos ellos ofrecen una relativa homogeneidad que sin embargo no invita a pensar en su coincidencia temporal sino en su asincronía. Tanto las principales características morfoestilísticas como las técnicas y fechas numéricas ofrecidas por varios yacimientos de la cercana región del Côa (Aubry 2009a, 2015) o del sitio de Medal, en el alto Sabor portugués (Figueiredo et al. 2014, 2016), han permitido acercarnos a su cronología gracias a los sólidos y abundantes paralelos documentados con el arte Magdaleniense y del ciclo artístico del final del Paleolítico de estos sitios, entre el final del Tardiglaciar y el Holoceno temprano, certificando así nuestras iniciales sugerencias cronológicas (Reis y Vázquez Marcos 2015).

3. El dispositivo iconográfico adscrito a la Prehistoria Reciente en el Arroyo de las Al- mas, con la presencia de un antropomorfo, un motivo zoomorfo indeterminable y más de 130 "uñadas del diablo", muestra tanto la especial localización e implantación de algunos de estas figuras llevadas a cabo por las tres principales técnicas de grabado conocidas, piqueteado, incisión y abrasión, como su relevante percepción visual, siendo su presencia novedosa en el contexto geográfico de la cuenca española del Duero.

4. Los análisis y comparación de las numerosas imágenes grabadas de la Edad del Hierro, équidos y ciervos principalmente, dentro de la categoría zoomorfa, además de motivos abstractos, armas o figuras humanas, con otros yacimientos catalogados en la cuenca del Duero portuguesa (Luís 2015; Neves y Figueiredo 2015; Reis 2014), nos ha permitido acercarnos a una parte muy relevante de sus significados, esencialmente socioeconómico y ritual, además de su más que segura relación con las élites ecuestres de estos grupos prehistóricos pre-romanos como sucede en otros conjuntos del territorio ibérico y europeo con los que también tienen múltiples paralelos gráficos (Royo Guillén 2005, 2009). Una propuesta cronológica ratificada, asimismo, por el arte mueble en contexto arqueológico del poblado fortificado de Castelinho (Santos et al. 2012), del que quizá no carezca Arroyo de las Almas, como apuntan los vestigios cerámicos observados a pie del panel del Núcleo II. De igual modo, las representaciones protohistóricas inventariadas reflejan, de una forma más acorde, la realidad gráfica de este período, que aparentemente parecía estar asociada, en la actual provincia de Salamanca, al hábitat castreño y a sus sistemas defensivos (Martín Valls y Carnicero 2008; Vázquez Marcos 2010) reavivando también la cuestión del arte de este período como frontera.

5. El arte rupestre agro-pastoril y popular de Época Moderna y Contemporánea en la provincia de Salamanca, además de conectado con las vivencias de las poblaciones rurales, parecía, a tenor de las escasas publicaciones que han abordado estas manifestaciones artísticas (García Medina 2014), ligado a soportes móviles, generalmente de uso pastoril. Sin embargo, la gran cantidad de vestigios gráficos encontrados, tanto en Arroyo de las Almas como otros sitios cercanos, sin prospectar ni publicar, nos lleva a concluir que las rocas aquí inventariadas son una mínima fracción de la realidad y que son muchos más los sitios de 
este período cronocultural. Destacar también, sobre el arte más reciente del Arroyo de las Almas, su homogeneidad estilística y temática, con un gran predominio de motivos abstractos, sobre todo reticulados, además de figuras humanas y animales junto a otros más raros, como pentalfas o ballestas, siendo muy pocas las representaciones de temática religiosa. Este vacío iconográfico es sorprendente, sobre todo si lo comparamos con el cercano valle del Côa y tal vez merezca una mayor atención de la que le hemos concedido en este artículo. Es cierto que también podríamos incluir las representaciones de pentalfas como parte del sentimiento religioso, pero pensamos que estas manifestaciones están más cerca de las creencias populares, siendo un claro desvío frente a las normas más ortodoxas en la religión oficial.

6. El estado de conservación del conjunto $\mathrm{y}$ de su arte rupestre es realmente bueno, pese a la intensa antropización del entorno, excepto en contadas ocasiones, como en el Núcleo II. Esta actividad humana, preferentemente la más reciente, y que se observa en algunos de los paneles grabados del conjunto, genera, en alguna ocasión, argumentadas dudas sobre su antigüedad a causa de las constantes superposiciones y similares pátinas como sucede en varias rocas del Núcleo I.

Como síntesis, y para finalizar, queremos destacar la perfecta integración del conjunto artístico del Arroyo de las Almas dentro del vasto espacio de la cuenca internacional del Duero que tiene como estratégico epicentro artístico la región del valle del Côa, aunque con su propia personalidad. Un extenso territorio donde se localiza el conjunto descrito, que nos permitirá no solo seguir avanzando en la mejor comprensión de las intensas redes de intercambio, que al menos desde Magdaleniense han sido aquí detectadas, y que tras lo observado, se hacen extensibles a ulteriores períodos cronoculturales al ser este un lugar de paso obligado además de privilegiado para el estudio de las complejas y polifacéticas motivaciones que se manifiestan tras el hecho de decorar las rocas a lo largo de los tiempos. Este descubrimiento también resulta especialmente importante para la comprensión de la ocupación y poblamiento del Águeda que desde el hecho gráfico parecía tener su cenit entre la segunda mitad del Tardiglaciar e inicios del Holoceno temprano, con Siega Verde como centro referencial (Vázquez Marcos 2018; Vázquez Marcos y Angulo Cuesta 2019). Sin embargo, y coincidiendo con un proceso de creciente segmentación territorial y de abandono de enclaves que previamente habían sido los ejes, se ocupan otros nuevos espacios, como el Arroyo de las Almas, que asumirán un rol cada vez más importante hasta adquirir su esplendor artístico en etapas postpaleolíticas.

\section{Fuentes de financiación}

La prospección y posteriores investigaciones desarrolladas por los autores de este artículo no recibieron concesión alguna de fondos provenientes de los sectores público, comercial o no lucrativo.

\section{Agradecimientos}

Agradecer a los arqueólogos del Parque Arqueológico do Vale do Côa, Dalila Correia, António Martinho Baptista y Jorge Sampaio, la visita realizada al conjunto rupestre en 2017, tras nuestra petición. Sus sugerencias y valiosas aportaciones han enriquecido esta modesta aportación al arte rupestre ibérico al igual que las realizadas, muy acertadamente, por parte de los/as evaluadores/as designados por el Consejo de Redacción de la revista Complutum.

\section{Bibliografía}

Alcolea, J. J.; Balbín, R. (2006): Arte Paleolítico al Aire Libre. El yacimiento rupestre de Siega Verde. Junta de Castilla y León, Salamanca.

Alcolea, J. J.; Balbín, R. (2008): El Yacimiento Rupestre de Siega Verde, Salamanca. Una visión de síntesis. En Balbín, R. (ed.) (2008), Arte Prehistórico Al Aire Libre en el Sur de Europa: 57-87. Junta de Castilla y León, Salamanca.

Aubry, T. (ed.) (2009a): 200 séculos da história do Vale do Côa: Incursões na vida quotidiana dos caçadores artistas do Paleolítico. IGESPAR, Lisboa.

Aubry, T. (2009b): Enquadramento geográfico. En Aubry 2009a: 21-27. 
Aubry, T. (2015): Peuplement de l'intérieur de la Péninsule Ibérique pendant le Paléolithique supérieur: où en est-on? ARPI, 03 Extra: 20-31.

Aubry, T.; Gameiro, C.; Santos, A.; Luís, L. (2017): Existe Azilense em Portugal? Novos dados sobre o tardiglaciar e o pré-boreal no Vale do Côa. En Arnaud, J. M.; Martins, A. (eds.) (2017), Arqueologia em Portugal. 2017 - Estado da Questão: 403-418. Associação dos Arqueólogos Portugueses, Lisboa.

Balbín, R.; Alcolea, J. J.; Santonja, M.; Pérez, R. (1991): Siega Verde (Salamanca). Yacimiento artístico paleolítico al aire libre. En Santonja, M. (ed.) (1991), Del Paleolítico a la Historia: 33-48. Museo de Salamanca, Salamanca.

Baptista, A. M. (1999): No tempo sem tempo: A arte dos caçadores paleolíticos do Vale do Côa. Com uma perspectiva dos ciclos rupestres pós-glaciares. Parque Arqueológico do Vale do Côa/Centro Nacional de Arte Rupestre, Vila Nova de Foz Côa.

Baptista, A. M. (2009): O paradigma perdido. O Vale do Côa e a Arte Paleolítica de Ar Livre em Portugal. Afrontamento, Lisboa.

Baptista, A. M. (2012): El Arte Paleolítico en Portugal. En Escobar, I.; Rodríguez, B. (eds.) (2012): Arte sin artistas: una mirada al Paleolítico: 305-338. Museo Arqueológico Regional, Alcalá de Henares, Madrid.

Baptista, A. M.; Reis, M. (2008): Prospecção da arte rupestre no Vale do Côa e Alto Douro Português: ponto da situação em Julho de 2006. En Balbín, R. (ed.) (2008), Arte Prehistórico Al Aire Libre en el Sur de Europa: 145-192. Junta de Castilla y León, Salamanca.

Baptista, A. M., Reis, M. (2011): A rocha gravada de Redor do Porco. Um novo sítio com arte paleolítica de ar livre no rio Águeda (Escalhão, Figueira de Castelo Rodrigo). Côavisão, 13: 15-20.

Benito del Rey, L. (1970): Monumento rupestre de Vilvestre (Salamanca). Zephyrus, 21-22: 161-170.

Benito del Rey, L.; Grande del Brío, R.; Sánchez, M. (1993): La Mesa de Los Curas. Un santuario rupestre prehistórico en La Fregeneda (Salamanca). Zephyrus, 46: 315-318.

Bueno, P.; Balbín, R. (2016): De cazadores a productores. Transiciones y tradiciones. Del neolític a l'edat del bronze en el Mediterrani occidental. Estudis en homenatge a Bernat Martí Oliver: 465-480. Servicio de Investigación Prehistórica del Museo de Prehistoria de Valencia, Serie de Trabajos Varios, 119 , Valencia.

Bueno, P.; Balbín, R.; Alcolea, J. J. (2008): Estilo V en el ámbito del Duero: Cazadores finiglaciares en Siega Verde (Salamanca). En Balbín, R. (ed.) (2008), Arte Prehistórico Al Aire Libre en el Sur de Europa: 259-286. Junta de Castilla y León, Salamanca.

Collado, H. (2008): Arte rupestre prehistórico en Extremadura: 1997-2006. En Balbín, R. (ed.) (2008), Arte Prehistórico Al Aire Libre en el Sur de Europa: 287-322. Junta de Castilla y León, Salamanca.

Collado, H.; García, J. J. (2007): Corpus de Arte Rupestre en Extremadura. Vol. II. Arte Rupestre en la Zepa de la Serena. Junta de Extremadura, Mérida.

Corchón, M. S.; Valladas, H.; Bécares, J.; Arnold, M.; Tisnerat, N.; Cachier, H. (1996): Datación de las pinturas y revisión del arte paleolítico de Cueva Palomera (Ojo Guareña, Burgos, España). Zephyrus, 49: 37-60.

D’Errico, F. (1994): L'art gravé azilien. De la technique à la signification. C. N. R. S., Paris.

Ferreira, A. B. (1978): Planaltos e Montanhas do Norte da Beira: Estudo de Geomorfologia. Centro de Estudos Geográficos, Lisboa.

Figueiredo, S.; Xavier, P.; Silva, A.; Neves, D.; Domínguez, I. (2014): The Holocene transition and post-palaeolithic rock art from the Sabor Valley (Trás-os-Montes, Portugal). En Medina-Alcaide, M. A., Romero-Alonso, A. J., Ruiz-Márquez, R. M., Sanchidrián-Torti, J. L., (eds.) (2014): Sobre rocas y huesos: las sociedades prehistóricas y sus manifestaciones plásticas: 193-203. Imprenta Luque.

Figueiredo, S.; Nobre, L.; Xavier, P.; Gaspar, R.; Carrondo, J. (2016): First approach to the chronological sequence of the engraved stone plaques of the Foz do Medal alluvial terrace in Trás-os-Montes, Portugal. ARPI, 04 Extra: 64-77.

Garcês, S. (2017): Cervídeos: Símbolos e Sociedade nos primórdios da agricultura no Vale do Tejo. Universidade de Trás-os-Montes e Alto Douro, Vila Real.

García-Diez, M.; Cacho, C. (2015): Beyond Leroi-Gourhan's Style IV: portable art at La Peña de Estebanvela Rock-shelter (Segovia, Spain). Journal of Anthropology and Archaeology, 3 (1): 23-36.

García-Medina, C. (2014): El arte popular de los pastores salmantinos. Instituto de las Identidades/ Diputación de Salamanca, Salamanca. 
Luís, L. (2015): Uma arte da guerra. O vale do Côa no final no I Milénio a.C. En Lee, S.; Baptista, A. M.; Fernandes, A. P. B. (eds.): Arte Rupestre do Vale do Côa: 91-114. Ulsan Petroglyph Museum, Ulsan.

Maida, G.; García-Diez, M.; Pastoors, A.; Terberger, T. (2018): Palaeolithic art at Grotta di Cala dei Genovesi, Sicily: A new chronology for mobiliary and parietal depictions. Antiquity, 92 (361): 38-55.

Martín-Valls, R. (1998): La Edad del Hierro. En Martín Rodríguez, J. L. (ed.) (1998): Historia de Salamanca. Vol. 1. Prehistoria y Edad Antigua: 123-178. Centro de Estudios Salmantinos, Salamanca.

Martín-Valls, R.; Carnicero, F. R. (2008): Las insculturas del castro de Yecla de Yeltes: nuevas perspectivas para su estudio. En Álvarez-Sanchís, J. R. (ed.) (2008), Arqueología Vettona. La Meseta Occidental en la Edad del Hierro. Zona Arqueológica, 12: 232-251. Museo Arqueológico Regional, Alcalá de Henares, Madrid.

Neves, D.; Figueiredo, S. (2015): Quinhentas placas gravadas da Idade do Ferro do sítio fortificado do Castelinho (Nordeste Portugal): temas figurados e padrões de distribuição. En Collado, H.; GarcíaArranz, J. J. (eds.) (2015): XIX International Rock Art Conference IFRAO 2015. Symbols in the Landscape: Rock Art and Its Context: 1589-1606. Instituto Terra e Memória, Tomar.

Pérez, P. P. (2011): La geología del yacimiento de Siega Verde. En Fernández-Moreno, J. J. ; Burón, M. (eds.) (2011): Siega Verde. Arte Paleolitico al Aire Libre: 20-25. Junta de Castilla y León, Salamanca.

Reis, M. (2011): Prospecção da arte rupestre do Côa: Ponto da situação em Maio de 2009. En Rodrigues, M. A.; Lima, A. C.; Santos, A. T. (eds.) (2011): Actas do V Congresso de Arqueologia-Interior Norte e Centro de Portugal: 11-123. Caleidoscópio/Direcção Regional de Cultura do Norte, Porto.

Reis, M. (2012) Mil rochas e tal...!: Inventário dos sítios da arte rupestre do vale do Côa. Portvgalia, 33: 5-72.

Reis, M. (2013): Mil rochas e tal...!: Inventário dos sítios da arte rupestre do vale do Côa ( $2^{\circ}$ parte). Portvgalia, 34: 5-68.

Reis, M. (2014): Mil rochas e tal...: Inventario dos sítios da arte rupestre do vale do Côa (conclusão). Portvgalia, 35: 17-59.

Reis, M.; Vázquez-Marcos, C. (2015): Arte rupestre en la frontera hispano-portuguesa: cuenca del río Águeda. ARPI, 03 Extra: 32-43.

Royo-Guillén, J. I. (2005): Las representaciones de caballos y de élites ecuestres en el arte rupestre de la Edad del Hierro de la Península Ibérica. Cuadernos de Arte Rupestre, 2: 157-200.

Royo-Guillén, J. I. (2009): El arte rupestre de la Edad del Hierro en la Península Ibérica y su problemática: aproximación a sus tipos, contexto cronológico y significación. Saldvie, 9: 37-69.

Ruiz-Zapatero, G. (1996): La prospección de superficie en la arqueología española. Quaderns de prehistòria i arqueologia de Castelló, 17: 7-20.

Santonja, M. (1998): Los tiempos prehistóricos. En Martín-Rodríguez, J. L. (ed..) (1998): Historia de Salamanca, Vol. 1. Prehistoria y Edad Antigua: 17-122. Centro de Estudios Salmantinos, Salamanca.

Santos, F.; Sastre, J.; Figueiredo, S. S.; Rocha, F.; Pinheiro, E.; Dias, R. (2012): El sitio fortificado del Castelinho (Felgar, Torre de Moncorvo, Portugal). Estudio preliminar de su diacronía y las plaquetas de piedra con grabados de la Edad del Hierro. Complutum, 23 (1): 165-179.

Santos, A. T.; Sanches, M. J.; Teixeira, J. C. (2015): The Upper Palaeolithic rock art of Portugal in its Iberian context. En Bueno, P.; Bahn, P. G. (eds.) (2015): Prehistoric Art as Prehistoric Culture. Studies in Honour of Professor Rodrigo de Balbin-Behrmann: 123-133. Archaeopress, Oxford.

Santos, A. T. (2017): A arte paleolítica ao ar livre da bacia do Douro à margem direita do Tejo: uma visão de conjunto. Universidade do Porto, Porto.

Santos Estévez, M. (2008): Petroglifos y paisaje social en la Prehistoria reciente del noroeste de la Península Ibérica. Xunta de Galicia: Consejo Superior de Investigaciones Científicas, CSIC, Instituto de Estudios Gallegos "Padre Sarmiento". TAPA: traballos de arqueoloxía e patrimonio, 38.

Sevillano, M. C. (1991): Grabados rupestres en la Comarca de la Hurdes (Cáceres). Universidad de Salamanca, Salamanca.

Steelman, K.; Lombera-Hermida, A.; Viñas-Vallverdú, R.; Rodríguez-Álvarez, X.; Carrera-Ramírez, F.; Rubio-Mora, A.; Fábregas-Valcarce, R. (2017): Cova Eirós: An Integrated Approach to Dating the Earliest Known Cave Art in NW Iberia. Radiocarbon, 59 (1): 151-164.

Teixeira, J. C.; Sanches, M. J. (2017): O abrigo rupestre da foz do rio Tua no contexto da arte paleolítica e pós-paleolítica do Noroeste da Península Ibérica. Portvgalia, 38: 9-48.

Vázquez Marcos, C. (2010): El Castro de Las Merchanas (Lumbrales, Salamanca) y sus Insculturas. En Cubas, N.; Hidalgo, D.; Salinas de Frías, M. (eds.) (2010): Arqueología, Patrimonio, Prehistoria e 
Historia Antigua de los Pueblos "Sin Pasado": ecos de la Lusitania en Arribes del Duero: 111-124. Ediciones Universidad de Salamanca, Salamanca.

Vázquez Marcos, C. (2018): El arte Paleolítico de Siega Verde (Serranillo, Salamanca, España): una sintética visión en el trigésimo aniversario de su descubrimiento. Estudos do Quaternário, 19: 63-82.

Vázquez Marcos, C.; Angulo Cuesta, J. (2019): Conoce Siega Verde. Arte Paleolítico al aire libre. Centro de Estudios Mirobrigenses y Excmo. Ayuntamiento de Ciudad Rodrigo. Trabajos de investigación, 12.

Vázquez Marcos, C.; Reis, M. (2019): Arroyo de las Almas (La Fregeneda, Salamanca): un nuevo sitio con arte Paleolítico al aire libre. Trabajos de Prehistoria, 76 (1): 138-146. 